\title{
La geopolítica de México en Centro América:iuna hegemonía regional?
}

ALBERTO ROCHA*

\section{Introducción}

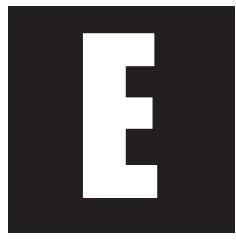

$\mathrm{n}$ trabajos anteriores he descrito y analizado situaciones y realidades nuevas en las que tanto México como Brasil están incursionando desde los años iniciales de esta primera década del 2000; estos dos Estados comenzaron a desplegar proyecciones geoeconómicas y geopolíticas sobre su entorno inmediato (la subregión de pertenencia) y su entorno mediato (la subregión vecina), además de jugar roles políticos destacados en su entorno lejano (la región latinoamericana y caribeña) y en su entorno remoto (el continente americano). En consecuencia, hemos propuesto y desarrollado las ideas de que estas situaciones y realidades son las de procesos de constitución de dos Estados con roles de "subhegemones", con sus respectivas funciones de "subhegemonía". ${ }^{1}$

Los primeros análisis y desarrollos que hemos realizado nos han permitido afirmarnos y persistir en estas exploraciones. Ahora, después de algún tiempo, contamos con mayores evidencias y datos empíricos para avanzar nuevas sistematizaciones. Seguimos preguntándonos: ¿Cómo y por

\footnotetext{
* Professor Investigador do departamento de Estudios Ibéricos y Latinoamericanos, Universidad de Guadalajara. México. 1 Alberto Rocha V: "México y Brasil en el proceso de integración regional de América Latina y el Caribe: ¿Rol de dos subhegemones?", Rev. Liminar No 1, Centro de Estudios Superiores de México y Centroamérica, Universidad de Ciencias y Artes de Chiapas, Chiapas-México, junio de 2003; "El posicionamiento débil y disperso de América Latina y el Caribe ante el Área de Libre Comercio de las Américas", Rev. Cenarios No 3 y 4, Grupo de Estudos Interdisciplinares sobre Cultura e Desenvolvimento, Universidade Estadual Paulista, Sao Paulo-Brasil, 2001-2002.
} 
qué México y Brasil se encuentran definiendo roles de "subhegemones"? ¿Son posibles tales roles y funciones en un espacio continental donde un Estado "superpotencia" ejerce una "supremacía" indiscutible, además de buscar redefinir su "hegemonía" (la que está en crisis)?

En este trabajo nos dedicaremos al caso de México. Ahora bien, para trabajar el tema de las relaciones geopolíticas de México con Centroamérica realizaremos cuatro aproximaciones: posicionamiento actual de México, antecedentes históricos de las relaciones, proceso de institucionalización de la cooperación y campo de acción de la relaciones. Concluiremos el trabajo con algunas ideas sobre la visión geopolítica de México.

La aproximación al posicionamiento estructural de México en el mundo y el continente americano, busca poner en evidencia las realidades de su condición de país semiperiférico y "subhegemón". La aproximación histórica conduce a la década de los años ochenta y a la década de los años noventa, donde se sientan los antecedentes y se inicia y profundiza la cooperación de México con Centroamérica. La aproximación institucional, centrada en la década de los años noventa e inicios de la primera década del año 2000, aborda el campo de acción de las relaciones geopolíticas y geoeconómicas de México con Centroamérica. Esta parte es central en el trabajo, pues se trata de analizar el Mecanismo de Diálogo y Concertación de Tuxtla-Gutiérrez y sus tres ámbitos de operación: 1. El ámbito político. 2. El ámbito del desarrollo. 3. El ámbito de la cooperación técnica regional. 4. El ámbito económico, comercial y financiero.A continuación presentaré mis hipótesis de trabajo:

HIPÓTESIS:

- Hipótesis 1: En el proceso de integración regional (PIR) de ALyC participan dos "subhegemones": El primero, México, como país semiperiférico, es un "nexo" (mediación y puente) entre el PIR de ALyC y el PIR de América del Norte (AN). El segundo, Brasil, también 
como país semiperiférico, es un "catalizador" (contribuye a materializar y plasmar) del PIR de ALyC.

- Hipótesis 2: En el proceso de integración regional de AN, solamente participa una "superpotencia" y “ex hegemón", Estados Unidos, que como país central y actor-jugador estratégico mundial, es un catalizador del PIR de AN.

- Hipótesis 3: En el proceso de integración continental (PIC) de las Américas, EE UU desempeña un rol continental independiente y es un catalizador del PIC de las Américas, además, es un condicionador y/o determinador del rol de los "subhegemones". México juega un rol "relativamente dependiente" en la subregión del Gran Caribe (América Central y el Caribe) porque es un "subhegemón" vecino y relativamente condicionado por el "ex hegemón". Brasil apuesta por un rol "relativamente independiente" en la subregión de América del Sur porque es un "subhegemón" distante y relativamente libre de control del "ex hegemón". Ahora bien, esto es posible porque tanto México como Brasil han logrado establecer y mantienen relaciones de "interdependencia asimétrica" con los EE.UU.

Los sistemas regionales y subregionales de integración en América Latina y el Caribe

El panorama de los procesos de integración regional y subregional de América Latina y el Caribe nos proporcionará un contexto necesario para nuestros análisis. Es un lugar común el conocimiento de las etapas por las que ha atravesado el proceso integrador latinoamericano y caribeño: primera etapa, años sesenta y setenta; segunda etapa, años ochenta y noventa. Además se estaría ingresando en una tercera etapa. En la primera etapa se inicia el proceso de integración regional y, poco después, se le complementa 
con algunos procesos de integración subregional. No nos detendremos mayormente en esta etapa.

La segunda etapa, es la más importante. En ella se configura el perfil básico de la integración regional y subregional de la región; perfil que todavía se mantiene vigente. Esta es una situación que combina un proceso inicial de integración regional, la CLAN-ALADI (con sus instituciones regionales como el PARLATINO, el SELA y el Grupo de Río); y seis procesos de integración subregionales, la $\mathrm{AEC}$ (que es sobre todo un esquema de cooperación), el G-3 (un TLC), el SICA, la CARICOM, la CAN y el MERCOSUR (estos cuatro procesos, Uniones Aduaneras imperfectas). En esta etapa, el proyecto de integración regional sigue vigente, aunque no se le impulsa mayormente; los procesos de integración subregional, a pesar de la crisis de muchos países, se mantienen y avanzan lentamente en su proceso integrador, sobre todo las cuatro uniones aduaneras. Además, se presenta una situación algo excepcional: los esquemas de integración subregional no demuestran una vocación de convergencia regional (en la el proyecto CLANALADI), tampoco demuestran una voluntad fuerte de avance en su proceso integrador interno, pero sí parece estar dispuestos a propiciar unas relaciones bilaterales entre ellos y entre los diversos Estados, dando lugar a un entramado enmarañado de relaciones comerciales, las que necesariamente se sitúan en un nivel más bajo de integración que el subregional. Este es el panorama de la integración de la región latinoamericana y caribeña hasta finales de la década de los años noventa.

Antes de avanzar, es importante anotar que en la década de los noventa los EE.UU. lanzan la Iniciativa de las Américas, propician la fundación del TLCAN (que incorpora un país grande de América Latina, México) e impulsan el proceso de Cumbres de las Américas con la finalidad de crear un ALCA, que además de Canadá y los EE.UU. debería incorporar a todos los países latinoamericanos y caribeños, menos Cuba. También es funda- 
mental recordar que los años noventa son unos muy marcados por la implementación de políticas neoliberales, muy acordes con el llamado Consenso de Washington. Entonces, ahora es muy evidente, que la segunda etapa y, sobre todo, la subetapa de los años noventa, ya había sido afectada por el proceso de integración regional de América del Norte (el TLCAN) y por el proceso de Cumbres de las Américas y las negociaciones abiertas para formar un ALCA. Así, lo que va quedando en claro es que los EE.UU., desde el TLCAN, habrían iniciado un proceso de redefinición de su hegemonía en el continente americano. El proceso de Cumbres de las Américas y las negociaciones para la creación de un ALCA, son muestras de las nuevas proyecciones geopolíticas y geoeconómicas en el hemisferio americano de los EE.UU. ${ }^{2}$

La tercera etapa, que se habría iniciado en año 2000 y que se encuentra en curso, todavía no nos ha mostrado todas sus potencialidades y posibilidades, pero algunos cursos ya están emplazados fuertemente. El proceso de negociaciones para el ALCA sigue su desenvolvimiento, no sin problemas, y ha logrado imponerse como la principal dinámica política externa de la región latinoamericana y caribeña. El proyecto-proceso de integración regional (CLAN-ALADI) se ha estancado y atraviesa una situación de crisis histórica (la imposibilidad de la unidad y de la autonomía de la región). Los seis procesos de integración subregional se muestran amenazados por la cercanía del ALCA (que deberá firmarse a inicios del 2005). Los acuerdos bilaterales siguen efervescentes. Las sociedades civiles se movilizan y demandan participación e inclusión en los procesos de integración. A todo lo cual, tenemos que sumar dos procesos muy similares. Estos son, los procesos de integración iniciados por el MERCOSUR con la CAN y por México con el SICA. Si bien los pasos iniciales de ambos procesos se

2 Alberto Rocha V: Configuración política de un mundo nuevo. Dimensiones políticas de lo global, lo suprarregional, lo posnacional y lo local, Universidad de Guadalajara, Jalisco-México, 2003. 
efectuaron durante la década pasada de los años noventa, es a partir del año 2000 que se desenvuelven con toda franqueza. México firma el año 2000 un TLC con los países centroamericanos del Triángulo del Norte (Guatemala, Honduras y el Salvador), que en realidad es uno firmado con Centroamérica, pues ya había firmado con anterioridad respectivos TLC con Costa Rica y Nicaragua y esta negociando uno con Panamá. El MERCOSUR, por iniciativa de Brasil y a partir de la Cumbre de Presidentes de Sudamérica del año 2000, inició negociaciones con los países de la CAN para formar una Zona de Libre Comercio de América del Sur, las que se concluyeron a fines de año pasado. En otras palabras, en respuesta al proceso de integración continental impulsado por los EE.UU., México y Brasil deciden impulsar procesos de integración subregionales mucho más vastos como el de Mesoamérica y el de Sudamérica. Y en estos momentos nos encontramos; en el posicionamiento de Mesoamérica y de Sudamérica ante Norteamérica. ¿Y dónde queda América Latina y el Caribe?

\section{Posicionamiento del "hegemón" y de los "subhegemones"}

Para profundizar el análisis en esta parte del trabajo, procederé a introducir algunos desarrollos teóricos alrededor del concepto de hegemonía. Según la perspectiva neomarxista de G. Kébabdjian, en su libro Les théories de l'économie politique internationale (1999), la hegemonía en las relaciones internacionales se manifiesta en la capacidad de influir los intercambios comerciales y monetarios, los flujos financieros, el conocimiento técnico, las reglas de juego, entre otros dominios. La capacidad de influencia se despliega de tal manera que "las opciones tomadas por los Estados no hegemónicos pero soberanos, libres de escaparse y de luchar, se acuerdan con aquellas del hegemón" (p. 176). De esta manera, Kébabdjian elabora la siguiente definición de hegemonía: "el sistema de relaciones de poder 
ejercido por un hegemón y que le permite estructurar el campo de acción posible de los otros actores" (p. 176).

Antes de continuar, es importante señalar que cuando hablamos de hegemonía siempre nos estamos refiriendo a una tríada: supremacía, hegemonía y liderazgo, en donde cada uno de los términos se diferencian por matices importantes. La supremacía implica imposición de un orden político en base a la dominación y la fuerza; el mando se logra en base a la coerción y la legalidad del orden se ha generado según el principio desnudo de "poder crea derecho". La hegemonía es la capacidad de dirección política en la creación y gestión de un orden político y de algunos regímenes internacionales; el mando se establece en base a cierta legitimidad y legalidad; la hegemonía implica algún mínimo de cooperación y siempre reposa sobre la supremacía. El liderazgo, es la capacidad de iniciativa de uno a varios actores para generar propuestas de orden y proyectos de regímenes internacionales; el mando se funda en la legitimidad, la legalidad y la cooperación; el líder ha logrado convertir en un sustrato profundo su supremacía o sublimar su deseo de dominación.

En realidad estamos ante tres tríadas conceptuales complementarias: potencia (o superpotencia)-hegemón-líder, supremacía-hegemonía-liderazgo y dominación-legitimidad-cooperación. Aún más, estas tres tríadas conceptuales se desdoblan en otras seis: tres horizontales y tres verticales. Veamos las tres tríadas verticales: potencia (o superpotencia)-supremacíadominación, hegemón-hegemonía-legitimidad y líder-liderazgo-cooperación. Estas tres tríadas son muy útiles para el análisis de los roles que juegan las potencias (o superpotencias), los hegemones y los líderes. Si nos pusiéramos en sintonía con los desarrollos teóricos de Joseph S. Nye Jr., habría que convenir que las potencias o superpotencias hacen uso extensivo del "poder duro" ("hard power" ) y que los hegemones y líderes recurren principalmente al "poder blando" ("soft power"). El "soft power" radica en "la 
capacidad de atraer y persuadir, más que de obligar"; "surge de lo atractivo que resulten los ideales políticos, la cultura y la política de un país". El "hard power" o "la capacidad coercitiva", "proviene del poderío militar y económico de una país". ${ }^{3}$ También, es posible escribir que las potencias o superpotencias son proclives a las acciones unilaterales y a las situaciones unipolares y que los hegemones y líderes prefieren las acciones multilaterales y las situaciones multipolares.

Desde está perspectiva, un hegemón (un estado central y potencia mundial principal) dispone de las siguientes capacidades: 1. Capacidad de ejercer hegemonía en el ámbito mundial, es decir cuenta con la capacidad de creación de organización (relaciones) y de orden (reglas) político internacional. 2. Capacidad de proyección mundial, por medio de una geoeconomía, una geopolítica y una geoestrategia. 3. Capacidad de generación de procesos de integración regional, con la finalidad de constituir macrosistemas de integración regional. 4. Capacidad de alcance geopolítico y geoeconómico continental, para generar procesos de integración continental. 5. Capacidad de intervención en temas prioritarios considerados de su interés nacional.

Desde una perspectiva derivada, un subhegemón (un estado semiperiférico y potencia regional o potencia media) ${ }^{4}$ reúne las siguientes características: 1. Capacidad de ejercer hegemonía en un ámbito regional, es decir cuentan con la capacidad generativa de organización y de orden regional. 2. Capacidad generativa de procesos de integración regional, medianamente importantes, es decir son capaces de impulsar la conformación de mesosistemas de integración regional. 3. Además los subhegemones tienen compromisos con el hegemón, pero su base natural de acción son los Estados periféricos vecinos (su propia subregión o microrregión) y cercanos

\footnotetext{
3 Joseph S. Nye Jr.: "poder y estrategia de Estados Unidos después de Irak", en Rev. Foreign Affairs en Español, Vol.3, No 3, ITAM, México D.F., julio-septiembre de 2003.

4 Un subhegemón podría ser también un Estado central que, por sus proyecciones geopolíticas y geoeconómicas, se comporta como una potencia regional.
} 
(los países de las subregiones o microrregiones vecinas). 4. También los subhegemones son más favorables a la cooperación y a la corrección de asimetrías en sus relaciones con los Estados periféricos y cercanos. 5. Los subhegemones pueden ser líderes regionales. 6. En resumen, los subhegemones cuentan con capacidad de iniciativa geopolítica y geoeconómica más allá de su entorno inmediato (su subregión), hasta llegar a su entorno mediato (la región).

Ahora bien, alcanzado este nivel del análisis, es necesario aportar algún esclarecimiento sobre la condición actual de EE.UU. en el Sistema Político Internacional. Diremos que EE.UU. es un ex-hegemón, es decir dejó de ser un hegemón en el mismo momento en que cayó el Muro de Berlín, finalizaron la bipolaridad mundial y la guerra fría (con la implosión de la Unión Soviética) y se instaló lo que se ha denominado como la postguerra fría. Así, desde este momento los EE.UU. son una superpotencia, cuya supremacía militar no tiene iguales, aunque si tiene pares (la Unión Europea y Asía Pacífico fundamentalmente) en el ámbito económico. Según Joseph S. Nye Jr., la política mundial es un "juego de ajedrez tridimensional". En el tablero superior, "el de los temas militares interestatales clásicos", "Estados Unidos probablemente seguirá siendo la única superpotencia en los próximos años". En esta dimensión, "tiene sentido hablar de unipolaridad o hegemonía en los términos tradicionales". En el tablero intermedio, que "incluye asuntos económicos entre estados", "la distribución del poder ya es multipolar". En esta dimensión, "no tiene mucho sentido calificar eso de 'hegemonía estadounidense'". En el tablero inferior, "el de los asuntos transnacionales", "el poder está ampliamente repartido y organizado de manera caótica entre actores estatales y no estatales". En esta dimensión, "no tienen mucho sentido calificar eso de 'mundo unipolar' o 'imperio estadounidense". ${ }^{5}$ 
Bien, como superpotencia militar y como potencia económica, los EE.UU. parecerían haber apostado más por el "hard power" (la intimidación, la dominación y la fuerza) que por el "soft pawer" (el convencimento, la legitimidad y la legalidad); lo que implica privilegiar el unilateralismo sobre el multilateralismo en su política exterior. De esta manera, podemos apuntalar que estamos experimentando el ejercicio directo de la supremacía de los EE.UU. en el sistema político internacional, sobre todo desde el arribo de George W. Bush a la Presidencia de los Estados Unidos. Pero esto no fue así durante el gobierno americano anterior. Bajo el pasado gobierno del presidente Bill Clinton, los EE.UU. parecían enrumbados por los caminos de la multilateralidad, de la multipolaridad y del "soft power" (una ideología neoliberal, hoy en franco retroceso en el mundo entero). ¿Cómo entender esta contradicción? Al parecer, estaríamos en una situación franca de conflictividad entre dos tendencias políticas, aquellas que atraviesan tanto la política interior como la política exterior de los EE.UU., y que además se han instalado conflictivamente en las arenas movedizas de la política internacional actual. Para resumir, estamos ante el experimento contradictorio de refundación de la hegemonía estadounidense en el mundo y en el continente americano.

\section{Relación entre el "hegemón" y los dos "subhegemones" y la formalización de las "subhegemonías" de México y Brasil}

Los EE.UU. buscarían redefinir su "hegemonía" (en crisis) en el mundo y el continente americano. En el mundo, los EE.UU. disponen de una "independencia relativa" entre sus pares (los otros Estados potencia reconocidos y los que emergen como tales), porque con ellos mantiene relaciones de interdependencia (económicas, políticas y militares). Por lo tanto, en este dominio el procesamiento de una nueva hegemonía (y de un 
nuevo orden) es todavía una cuestión abierta. En el continente americano, los EE.UU. juegan un rol principal y preponderante, asimismo mantienen la iniciativa en todos los dominios. En este dominio los EE.UU. disponen de una "independencia absoluta o casi absoluta"; por ello el proceso de refundación de su hegemonía es más dinámico y parece estar muy cercano. Veamos este proceso. La finalización de la bipolaridad mundial y de la guerra fría, trajo consigo la crisis para el Sistema Interamericano (el Sistema Interestatal Continental, la OEA y el TIAR); en consecuencia, desde inicios de la década de los noventa, se ha empezado un proceso para su reestructuración paulatina. Este proceso se explicitó debidamente con el inicio del proceso de Cumbres de las Américas en Miami, el año de 1994. En términos generales, el proceso de reestructuración en curso se desenvuelve sobre tres ejes principales: la creación del ALCA (eje económico), la reforma de la OEA (eje político) y la superación del TIAR (eje militar), pero su alcance temático es mucho mayor. En otras palabras, los EE.UU. buscan redefinir su hegemonía en el hemisferio a partir de tres ideas fundamentales: libre comercio (concreción de unos TLC o de un ALCA para todo el continente), democracia representativa (Carta Democrática Interamericana) y seguridad hemisférica (unas Fuerzas Armadas Continentales). Todo esto bajo la cobertura ideológica neoliberal del llamado Consenso de Washington (hoy cuestionado y en crisis). Ahora bien, es importante comprender la importancia que el gobierno pasado y el gobierno actual norteamericanos han impreso a cada uno de los tres ejes. Fue muy evidente que para Bill Clinton el eje económico era primero y central, seguía el eje político y después el militar. En cambio, con el gobierno de George W. Bush el ordenamiento de los ejes cambió: el eje militar es primero y central, sigue el eje económico y después el político. En el gobierno de George W, Bush el recurso del "hard power" está a la vista de todos, lo que no deja de tener consecuencias en el proceso de Cumbres de las Américas. 
En este proceso de reestructuración del Sistema Interamercano, los Estados nacionales están jugando los roles más importantes, aunque también están jugando roles destacados algunos de los sistemas de integración regional y subregional de las América Latina (la CAN, el SICA y el MERCOSUR), el Caribe (la CARICOM) y América del Norte ( el TLCAN). En cuanto al rol que juegan los Estados nacionales americanos, es fácil percibir una jerarquía de roles entre ellos: un primero, un segundo, dos terceros, algunos cuartos y así sucesivamente. El primero, los EE.UU., está empeñado en refundar su hegemonía en el continente ( y en el mundo). A falta de esta hegemonía ejerce supremacía. El segundo, Canadá, es una potencia sin vocación alguna de hegemonía en el continente. Los dos terceros, México y Brasil, de manera explícita desde el año 2000, decidieron ensayarse como "subhegemones" en sus respectivas vecindades regionales; México en Centroamérica y Brasil en Sudamérica. Siguen los cuartos, Chile, Argentina y Costa Rica, y allí nos detenemos. De acuerdo con esta jerarquía interestatal continental, el Estado primero es "independiente"; el Estado segundo es el de "mayor independencia relativa"; los Estados terceros los de "menor independencia relativa"; siguen los Estados cuartos, que ya se encuentran el situación de dependencia muy clara (aunque aquí también se pueden establecer grados).

En cuanto a México y Brasil y a la formalización de sus roles como "subhegemones", el punto de partida del análisis es su condición de Estados semiperiféricos y Estados terceros en la jerarquía del sistema interestatal americano. El punto siguiente del análisis son sus relaciones con el Estado primero, los EE.UU. México y Brasil son Estados grandes, primeros y líderes entre los Estados latinoamericanos y caribeños, pero como terceros en la jerarquía interestatal continental, lo que implica una relación comparativa con los EE.UU. y Canadá, son los Estados de "menor independencia relativa". En seguida, si solamente tomamos el conjunto de los Estados latinoamericanos y caribeños, en el periodo que va desde mediados de los 
años ochenta, pasando por los años noventa y todo lo que va de los años 2000, el Estado que muestra disponer de "mayor independencia relativa" es Brasil, mientras que México aparece como el Estado que dispone de "menor independencia relativa". ${ }^{6}$ Ahora bien, para diferenciar con mayor nitidez las situaciones de estos dos Estados, hemos escrito de manera hipotética (en la introducción) que Brasil juega un rol "relativamente independiente" y que México juega un rol "relativamente dependiente". Y estas dos situaciones son posibles debido a que los dos Estados han logrado establecer relaciones de "interdependencia asimétrica" con los EE.UU. y de "interdependencia imperfecta" en el mundo. ${ }^{7}$ Entonces, México y Brasil se han posicionado de tal manera respecto de los EE.UU. y entre ellos mismos que han logrado establecer una relación triangular: en el vértice superior los EE.UU. y en los dos vértices inferiores México y Brasil. Los EE.UU. se empeñan en redefinir o refundar su hegemonía en el continen-

6 Ha sido Mario Ojeda, en su obra Alcances y Límites de la Política Exterior de México (El Colegio de México, México D.F., 2001; la primera edición data de 1976), quien ha postulado la tesis de la "mayor independencia relativa" de México, dentro del conjunto de Estados latinoamericanos y caribeños, respecto de los EE.UU, durante el periodo de la post-guerra hasta mediados de los años setenta. Mario Ojeda escribe lo siguiente: "En un primer acercamiento la política exterior mexicana resulta en gran medida peculiar cuando se le compara con la del resto de América Latina: no obstante la vecindad directa, la fuerte dependencia económica respecto de los Estados Unidos y de que ésta se haya dado en buena parte durante un periodo convulsionado por la guerra fría, la política mexicana ha podido seguir un curso de mayor independencia relativa" (p. 14). "Sin embargo, si bien el país es miembro del sistema interamericano y necesariamente parte de la zona de influencia de los Estados Unidos, es un hecho que al menos durante el periodo analizado pudo mantener dentro del área una política exterior que bien puede calificarse de mayor independencia relativa" (p. 55). También es sumamente importante anotar el análisis comparativo que Mario Ojeda realiza entre Brasil y México. Respecto de Brasil escribe que "aun a pesar de ser el mayor y más poderoso país de Latinoamérica, no ha seguido, en lo general, una política que pueda calificarse de independiente frente a los Estados Unidos, pero obviamente porque no ve en ello su interés u otra razón alguna" (p.110). En cuanto a México anota que "parece tener no solamente el interés, sino aun la necesidad de seguir una política más cautelosa frente a los Estados Unidos, de lo cual resulta un grado de disidencia mayor" (pp. 110 y 111). Estas notas son sumamente importantes para nosotros, pues la tesis central está magistralmente sustentada (la "mayor independencia relativa" de México) y es muy convincente la tesis secundaria (una política exterior que no puede calificarse de independiente, la de Brasil). Además, el autor de la obra citada anota que si las dos políticas exteriores muestran dichas características es porque México practicó "un grado de disidencia mayor" (p. 111) y Brasil aplicó "una política deliberada de estrecha asociación" (p. 110) con los Estados Unidos. Mi hipótesis de trabajo es que estas situaciones de México y Brasil respecto de los Estados Unidos, en la etapa de los ochenta, noventa y lo que va del 2000, se habrían cambiado o invertido: México ha optado por la "asociación" y Brasil por la "disidencia", lo que implica dos proyectos geoeconómicos y geopolíticos diferentes y, en consecuencia, dos políticas exteriores diferentes.

7 En concepto de "interdependencia compleja" y de "interdependencia asimétrica" se los debemos a Keohane, Robert O. y Nye, Joseph S.: Poder e interdependencia. La política mundial en transición, GEL, Argentina 1988. También se puede consultar Keohane, Robert O.: Instituciones internacionales y poder estatal. Ensayos sobre teoría de las relaciones internacionales, GEL, Argentina, 1993. El concepto de interdependencia compleja está reservado para el análisis de las relaciones que establecen países desarrollados $y$, hasta cierto punto, pares en términos de sus capacidades. Por ello es que este concepto se entiende muy bien como "dependencia mutua", "beneficios mutuos" y "reciprocidades mutuas". El concepto de interdependencia asimétrica, en cambio, está reservado para el análisis de las relaciones que se pueden establecer entre países desarrollados y países en vías 
te. México y Brasil se esfuerzan en definir y fundar sus subhegemonías en sus respectivas regiones, Mesoamérica (Sur-Sureste de México y Centroamérica) y Sudamérica(MERCOSUR + CAN) respectivamente. En estos esfuerzos, México logra formalizar una "hegemonía subordinada relativamente" y Brasil logra formalizar una "hegemonía autonomizada relativamente" en relación con los EE.UU. Esto es así porque México acepta relativamente y Brasil resiste relativamente la redefinición o refundación de la hegemonía de los EE.UU. Aún más, mientras México se establece como un subhegemón "nexo" entre América del Norte y América del Centro (y América del Sur y el Caribe); Brasil se establece como un subhegemón "catalizador" en Sudamérica (y en América latina y el Caribe). ${ }^{8}$ Finalmente, las relaciones entre los dos subhegemones, de acuerdo con sus funciones de "nexo" o de "catalizador", se desenvuelven entre la cooperación relativa (que implica el acuerdo relativo) y el conflicto relativo (que implica el desacuerdo relativo). ${ }^{9}$

\section{Política exterior, geopolítica y geoeconomía de México}

Una buena comprensión de la política exterior de México es fundamental para emprender el análisis de su geopolítica y de su geoeconomía. No me propongo en este trabajo ingresar en profundidad al análisis de la

\footnotetext{
de desarrollo y que sobresalen por su situación intermedia, es decir, países que son desiguales (no son pares). En este caso el concepto da cuenta de la dependencia mayor de una parte respecto de la otra, de los beneficios menores y de los esfuerzos mayores de una parte (de la parte menos desarrollada). En esta medida, los países en vía de desarrollo son poco sensibles y muy vulnerables. Por ello es que Jorge Chabat propone y prefiere el concepto de "interdependencia imperfecta", que busca medir "el grado de integración de una unidad a las redes mundiales de interdependencia", al concepto de interdependencia asimétrica, que es solamente "útil para medir la capacidad de negociación de una unidad estatal (o no estatal) en una determinada relación de interdependencia". Consultar Jorge Chabat, "La integración de México al mundo de la posguerra fría: del nacionalismo a la interdependencia imperfecta", en A. Borja, G. González y B. J. R. Stevenson (Coordinadores), Regionalismo y poder en América: los límites del neorrealismo, CIDE/Miguel Ángel Porrua, México D.F., 1996.

8 Alberto Rocha V: "México y Brasil en el proceso de integración regional de América Latina y el Caribe: ¿Rol de dos subhegemones?, op.cit.

9 Alberto Rocha V: “El posicionamiento débil y disperso de América Latina y el Caribe ante el Área de Libre Comercio de las Américas", op.cit.
} 
Política Exterior de México, pero algunas notas generales son imprescindibles para poder continuar en el propósito. Antes del Gobierno de Miguel de la Madrid, la política exterior de México estuvo fundada en un conjunto de principios, resultado de la síntesis de la "Doctrina Juárez", la "Doctrina Carranza" y la "Doctrina Estrada"..$^{10}$ Pero nosotros no nos ocuparemos de este periodo histórico, sino más bien nosotros abordaremos el periodo que se inicia bajo la presidencia de Miguel de la Madrid. Según algunos analistas, la política exterior de México mantiene una continuidad desde el Gobierno de Miguel de la Madrid (1982-1988), periodo en que se da un cambio fundamental respecto del periodo histórico anterior, hasta el Gobierno de Ernesto Zedillo (1994-2000); de allí para adelante, la política exterior durante el actual Gobierno de Vicente Fox (que se inicia en el 2000) se caracterizaría por mantener la continuidad en un contexto de introducción de cambios paulatinos. ${ }^{11}$ En palabras de uno de los analistas, Rafael Velásquez Flores, "el argumento central es que hay más continuidad que cambio en la política exterior de Vicente Fox con respecto a las administraciones de Salinas de Gortari y Ernesto Zedillo". ${ }^{12}$ Según el mismo Rafael Velásquez el continuismo se puede observar en cuatro factores importantes; de los cuales solamente nosotros citaremos dos: 1. "La política exterior mexicana se mantiene como un instrumento fundamental para promover el desarrollo

\footnotetext{
10 Los enunciados de las Doctrinas Juárez, Carranza y Estrada solamente quedaron plasmados en la Constitución Política de los Estados Unidos Mexicanos después de su reforma en el año de 1987/88, esto cuando finalizaba el Gobierno de Miguel de la Madrid. En el artículo 89 de la Constitución se anotan los principios de la política exterior del Estado mexicano: la autodeterminación de los pueblos; la no intervención; la solución pacífica de las controversias; la proscripción de la amenaza o el uso de la fuerza en las relaciones internacionales; la igualdad jurídica de los Estados; la cooperación internacional para el desarrollo; y la lucha por la paz y la seguridad internacionales. Sobre estas importantes cuestiones de la Política Exterior de México y la formulación de las Doctrinas, Juárez, Carranza y Estrada, consultar de Asmara González Rojas, Análisis comparativo de los fundamentos de la Política Exterior Estadounidense y Mexicana, Tesis de Licenciatura en Relaciones Internacionales, Departamento de Estudios Sociopolíticos y Jurídicos, Instituto Tecnológico y de Estudios Superiores de Occidente-ITESO, abril de 2003. Sin ninguna, es esencial también el libro de Mario Ojeda, Alcances y Límites de la Política Exterior de México, op.cit.

11 Esta tesis es sustentada por los autores de los trabajos más importantes del libro de Rafael Velásquez Flores (coordinador): La política exterior de México bajo un régimen democrático. ¿Cambio o continuidad?, Plaza y Valdés Editores, México D.F., 2002. Entre los trabajos más importantes de esta obra, podemos citar tres de ellos: Rafael Velásquez Flores: "El proyecto de política exterior de Vicente Fox: ¿Continuidad o Cambio?; Alejando Chanona: “La política exterior de México, el cambio democrático y los retos frente a la nueva arquitectura internacional"; Eduardo Roldán y Dámaso Morales: "Fox: una política exterior en transición".

12 Rafael Velásquez Flores: “El proyecto de política exterior de Vicente Fox: ¿Continuidad o Cambio?", en La política exterior de México bajo un régimen democrático. ¿Cambio o Continuidad?, op.cit., p. 18.
} 
económico". 2. "Las relaciones de México con las diferentes regiones del mundo y con los países clave prácticamente continúan con las mismas líneas que las últimas administraciones priístas". Por cuestiones fundamentales, los países de mayor importancia par el primer año de Gobierno de Fox fueron Estados Unidos y Cuba. Sobre Estados Unidos el autor expresa lo siguiente: "la relación bilateral con Estados Unidos no sólo se mantiene en el mismo carril, sino que se hace más intensa y, por lo tanto, mejora en términos generales". En segundo orden se encuentra Europa, que "sigue siendo estratégica en términos de buscar inversiones". Finalmente, América Latina y el Caribe "continúan siendo las últimas prioridades de México". En cuanto al cambio y a la innovación, el mismo autor, enumera tres de ellos: "una mayor capacidad de negociación internacional, especialmente frente a Estados Unidos"; "una división real de poderes modificaba sustancialmente el proceso de toma de decisiones de la política exterior de México"; y, "el ímpetu democrático hizo que Vicente Fox colocara dos temas en la agenda de política exterior que anteriormente no tenían tanta importancia: derechos humanos y democracia".

Hasta aquí hemos dado algunos pasos sustantivos, pero todavía hacen falta dar algunos más. Esto con la finalidad profundizar un poco más sobre los temas del cambio y de la continuidad de la política exterior y, sobre todo, respecto de la especificidad de la política exterior del actual Presidente Vicente Fox. En un trabajo importante sobre la actual política exterior de México, Érika Ruiz Sandoval escribe que "quizá la única dependencia que inició este sexenio con un plan de navegación claro fue la Secretaría de Relaciones exteriores, gracias a que su titular, Jorge Castañeda, había trazado un mapa de lo que sería la política exterior durante este primer gobierno de la alternancia". ${ }^{13}$ Según esta investigadora, el plan era una "mezcla de cambio y de continuidad" y se basaba en tres grandes pilares o ejes: "El primero era sin duda audaz: había que profundizar la relación con América del Nor- 
te, particularmente con Estados Unidos". "El segundo pilar, mucho más tradicional, consistía en buscar afanosamente la diversificación política y comercial a partir de las relaciones existentes con los socios de América Latina y Europa". "El tercer eje, de nuevo una mezcla de tradición y cambio, tenía como objetivo incrementar la participación de México en foros multilaterales". ${ }^{14}$ Bien, que no queda duda sobre la importancia que revisten estos tres ejes en la política exterior de México, lo cual es esencial tener presente en los análisis de la actual geopolítica y geoeconomía de México.

La geopolítica de México

En el punto tres de este trabajo, hemos percibido cómo la geopolítica del Estado mexicano se precisa por medio de un ejercicio de posicionamiento ante el Estado norteamericano. Este ejercicio arroja como resultado una "subhegemonía". Ahora, además, podemos añadir que dicho posicionamiento necesita de un contexto adecuado; este contexto es Norte América y el Continente de América. En este contexto, México sobresale por su pertenencia al TLCAN, su participación en las negociaciones del ALCA y su intervención en el proceso de Cumbres de las Américas. Pero, como lo hemos visto anteriormente, en estos tres campos de acción los EE.UU. se encuentran redefiniendo un nuevo proyecto de hegemonía continental. En el TLCAN es crucial (aunque no indiscutible) el rol que juega EE.UU. El ALCA es un proyecto de mercado continental muy afín a los intereses norteamericanos. El proceso de Cumbres de las Américas, si bien es un proceso complejo y multidimensional donde los Estados y los esquemas de integración más importantes juegan sus respectivos roles, también está muy marcado por los intereses del Estado primero en la jerarquía interestatal americana; puesto que aquí se está diseñando el nuevo Sistema Interamercano. Ante y en este contexto México se "adecua" y "adapta" y

14 Sobre este tema consultar los trabajos de Jorge G. Castañeda: "Apuntes de política exterior para el gobierno de Vicente Fox: 2000-2006", en Carlos Elizondo y Luis Maira (editores), Chile-México, dos transiciones frente a frente, CIDE, México D.F., 2000; "Los ejes de la política exterior de México", Rev. Nexos, México D.F., diciembre de 2001. 
también "acepta" relativamente las determinaciones de la refundación de la hegemonía estadounidense. Aquí una aclaración, cuando escribimos "aceptación relativa", estamos diciendo que dicho Estado, si bien mantiene unos márgenes de decisión y acción muy importantes, no puede salirse de tal contexto, no puede apartarse de los ejes principales de lo proyectado en cada campo de acción y menos puede oponerse a los objetivos definidos en cada campo de acción. Dicho Estado puede jugar en tal contexto, puede apoyar la construcción de los ejes principales de cada campo, puede aportar a la mejor elaboración de los objetivos de cada campo de acción y puede hacer pasar sus intereses nacionales; y todo ello dependerá de sus potencialidades para posicionarse en tal contexto y de sus capacidades diplomáticas para negociar.

Ahora bien, el contexto que acabamos de analizar, de alguna manera, logra hacer extensivas sus determinaciones en el seno del sistema interestatal internacional y de la Organización de las Naciones Unidas, es decir al interior del sistema político internacional (en franco proceso de transformaciones). En este contexto mayor, los EE.UU. (superpotencia militar y potencia económica) también juegan roles de primer orden, junto a otras potencias mundiales (sean Estados nacionales o sistemas de integración regional) y a otras potencias regionales o medias. En todo caso, desde estas consideraciones, es posible analizar el rol destacado del Estado Mexicano en política internacional. México forma parte de muchos mecanismos multilaterales como: el Consejo de Seguridad de la ONU, la OMC, la OCDE, de UNESCO; la OEA y de las Cumbres de las Américas; del Grupo de Río, del Parlatino, del SELA, del Mecanismo de Diálogo y Concertación de TuxtlaGutiérrez, entre otros importantes.

La geoeconomía de México

La geoeconomía de México se puede explicar a partir de dos de sus rasgos centrales: 1. Sumamente diversificada y con vocación mundial. 2. Extremadamente vinculada con América del Norte y especialmente con- 
centrada con los EE.UU. Esta es casi una situación paradójica y recurro a una metáfora para explicarla. El alma de México mira el mundo y tiene vocación mundial; el cuerpo de México se encuentra anclado en América del Norte y vinculado con los Estados Unidos. Políticamente México está presente en el mundo entero y deja escuchar su voz; económicamente México es persistente con América del Norte y insistente con los Estados Unidos.

\section{A continuación presentamos el Cuadro: Tratados y Acuerdos}

Comerciales de México (ver figura 1), donde se encuentran los Tratados y Acuerdos firmados por México con diversos países y regiones del mundo. En este cuadro se puede constatar el alcance y diversificación mundiales del comercio mexicano: presente en el nivel internacional y global (léase la $\mathrm{OMC}$ ) y en todas las regiones del mundo.

Cuadro 1 - Tratados y acuerdos comerciales de México

\begin{tabular}{|c|c|c|}
\hline Internacionales y globales & Fecha de firma & Fecha de vigencia \\
\hline $\begin{array}{c}\text { Organización Mundial } \\
\text { de Comercio }\end{array}$ & 15/abril/1994 & 01/enero/1995 \\
\hline Región Europa & Fecha de firma & Fecha de vigencia \\
\hline $\begin{array}{l}\text { Tratado de Libre Comercio } \\
\text { con la Comunidad Europea }\end{array}$ & Febrero/1995 & 01/julio/2000 \\
\hline $\begin{array}{c}\text { Tratado de Libre Comercio } \\
\text { con la Asociación Europea } \\
\text { de Libre Comercio }\end{array}$ & $27 /$ nov $/ 2000$ & $\begin{array}{c}\text { México, Noruega y Suiza } \\
01 / \text { julio/2001 } \\
\text { México e Islandia } \\
\text { 01/octubre/2001 } \\
\text { México y Liechtensein } \\
\text { 01/nov/2001 }\end{array}$ \\
\hline Región Medio Oriente & Fecha de firma & Fecha de vigencia \\
\hline $\begin{array}{l}\text { Tratado de Libre } \\
\text { Comercio con Israel }\end{array}$ & 10/abril/2000 & 01/julio/2000 \\
\hline Región Asia Pacífico & Fecha de firma & Fecha de vigencia \\
\hline $\begin{array}{c}\text { Asia Pacífic Economic } \\
\text { Cooperation }\end{array}$ & 17-19/nov/1993 & \\
\hline $\begin{array}{c}\text { Tratado de Libre } \\
\text { Comercio con Singapur }\end{array}$ & 14/nov/2000 & \\
\hline $\begin{array}{c}\text { Tratado de Libre } \\
\text { Comercio con Japón }\end{array}$ & negociaciones & negociaciones \\
\hline Continente Americano & Fecha de firma & Fecha de vigencia \\
\hline $\begin{array}{c}\text { Área de Libre Comercio } \\
\text { de las Américas }\end{array}$ & negociaciones (desde 1998) & negociaciones \\
\hline Región América del Norte & Fecha de firma & Fecha de vigencia \\
\hline $\begin{array}{c}\text { Tratado de Libre Comercio } \\
\text { América del Norte }\end{array}$ & 17/dic/1992 & 01/enero/94 \\
\hline
\end{tabular}


Continuação..

\begin{tabular}{|c|c|c|}
\hline $\begin{array}{c}\text { Región América Latina } \\
\text { y el Caribe }\end{array}$ & Fecha de firma & Fecha de vigencia \\
\hline $\begin{array}{l}\text { Sistema Económico } \\
\text { Latinoamericano }\end{array}$ & 17/oct/1975 & \\
\hline $\begin{array}{c}\text { Asociatión Latinoamericana } \\
\text { de integración }\end{array}$ & 12/agosto/1980 & \\
\hline $\begin{array}{l}\text { Sub-región de } \\
\text { Centroamérica }\end{array}$ & Fecha de firma & Fecha de vigencia \\
\hline $\begin{array}{c}\text { Tratado de Libre } \\
\text { Comercio con Costa Rica }\end{array}$ & 5/abril/1984 & 01/enero/1995 \\
\hline $\begin{array}{c}\text { Tratado de Libre } \\
\text { Comercio con Panama }\end{array}$ & negociaciones (desde 1996) & negociaciones \\
\hline $\begin{array}{c}\text { Tratado de Libre } \\
\text { Comercio con Nicaragua }\end{array}$ & 18/dic/1997 & 01/julio/1998 \\
\hline $\begin{array}{l}\text { Tratado de Libre Comercio } \\
\text { con el Triangulo del Norte }\end{array}$ & 28-29/junio/2000 & $01 / 01 / 2002$ \\
\hline Plan Puebla-Panamá & 8 y 12 marzo/2001 & 15/junio/2001 \\
\hline Sub-región del Caribe & Fecha de firma & Fecha de vigencia \\
\hline $\begin{array}{c}\text { Convenio Constitutivo de } \\
\text { la Asociación de Estados } \\
\text { del Caribe }\end{array}$ & 24/junio/1994 & 04/agosto/1994 \\
\hline $\begin{array}{c}\text { Tratado de Libre Comercio } \\
\text { con Trinidad y Tobago }\end{array}$ & negociaciones (desde 1998) & negociaciones \\
\hline $\begin{array}{l}\text { Sub-región de } \\
\text { América del Sur }\end{array}$ & Fecha de firma & Fecha de vigencia \\
\hline $\begin{array}{l}\text { Tratado de Libre Comercio } \\
\text { con Colombia y Venezuela }\end{array}$ & 13/junio/1994 & 01/enero/1995 \\
\hline $\begin{array}{c}\text { Tratado de Libre } \\
\text { Comercio con Bolivia }\end{array}$ & 10/sep/1994 & 01/enero/1995 \\
\hline $\begin{array}{c}\text { Tratado de Libre } \\
\text { Comercio con Chile }\end{array}$ & 01/octubre/1998 & 01/agosto/1999 \\
\hline $\begin{array}{l}\text { Acuerdo de complementación } \\
\text { económica n. } 5\end{array}$ & 29/dic/1999 & 01/marzo/2001 \\
\hline $\begin{array}{l}\text { Acuerdo de complementación } \\
\text { económica n. } 8\end{array}$ & $\begin{array}{l}\text { 18/junio/2002 } \\
\text { (prorrogación) }\end{array}$ & \\
\hline $\begin{array}{l}\text { Acuerdo de complementación } \\
\text { económica }\end{array}$ & 03/julio/2002 & \\
\hline $\begin{array}{l}\text { Acuerdo de complementación } \\
\text { económica }\end{array}$ & 05/julio/2002 & \\
\hline Acuerdo de alcance parcial & negociaciones & negociaciones \\
\hline $\begin{array}{l}\text { Acuerdo de complementación } \\
\text { económica }\end{array}$ & negociaciones & negociaciones \\
\hline $\begin{array}{c}\text { Tratado de Libre Comercio } \\
\text { con Argentina }\end{array}$ & negociaciones & negociaciones \\
\hline
\end{tabular}

REALIZACIÓN:

GIIPRAL - GRUPO de INVESTIGACIÓN sobre INTEGRACIÓN POLÍTICA REGIONAL en AMÉRICA LATINA; constituido por el Dr. Alberto Rocha Valencia y los Egresados de la Lic. en Estudios Internacionales: Daniel E. Morales y Aldo Ponce Margarito. 
Ahora miremos las cifras del comercio de México con las diversas regiones del mundo (Cuadro: México, importaciones y exportaciones con cada una de las regiones del mundo, 1993-2002, (ver figura 2).

Comencemos con las exportaciones. En el cuadro encontramos que durante los años de 1993 al 2002, México estableció una jerarquía general de regiones para sus exportaciones: 1. América del Norte. 2. Europa. 3. Sudamérica. 4. Asia. 5. Antillas. 6. Centroamérica. 7. África. 8. Oceanía. El primer lugar es indiscutible con el $85.72 \%$ y el $90.73 \%$ de las exportaciones, en 1993 y 2002 respectivamente. Además el porcentaje de las exportaciones hacia esta región fueron en ascenso en la década estudiada. El segundo lugar con $5.20 \%$ y 3.25 de las exportaciones, en 1993 y 2002 respectivamente, también se encuentra consolidado. Además, el porcentaje de las exportaciones hacia esta región fueron en descenso en la década analizada. Sigue Sudamérica en el tercer lugar. Aquí una primera remarca. Si sumamos las exportaciones hacia Sudamérica, Centroamérica y las Antillas, la región de América Latina y el Caribe se situaría en el segundo lugar. Ahora la segunda remarca. Del total de exportaciones de México, si bien Norteamérica aparece como una región privilegiada, en realidad tal privilegio es para con los EE.UU. con el $82.70 \%$ y $88.98 \%$ de las exportaciones, en 1993 y 2002 respectivamente. En realidad, el ascenso del porcentaje de las exportaciones es con los EE.UU. más que con Norteamérica. Canadá solamente representa el $3.01 \%$ y el $1.75 \%$ de las exportaciones mexicanas, en 1993 y 2002 respectivamente; lo que es bastante semejante a las exportaciones realizadas con Sudamérica. Y este porcentaje de exportaciones también fue a la baja.

En cuanto a las importaciones de México con las regiones del mundo, también encontramos una jerarquía de ellas: 1. Norteamérica. 2. Asía. 3. Europa. 4. Sudamérica. 5. Oceanía, Centroamérica y Antillas. 6. África. Con Norteamérica las importaciones se mantienen en primer lugar, pero van a la baja durante la década; de $71.09 \%$ a 65.83\%, para 1993 y 2002 respectivamente. Indudablemente, esta tendencia a la baja fue causada 
Sociologias, Porto Alegre, ano 8, no 16, jul/dez 2006, p. 308-359

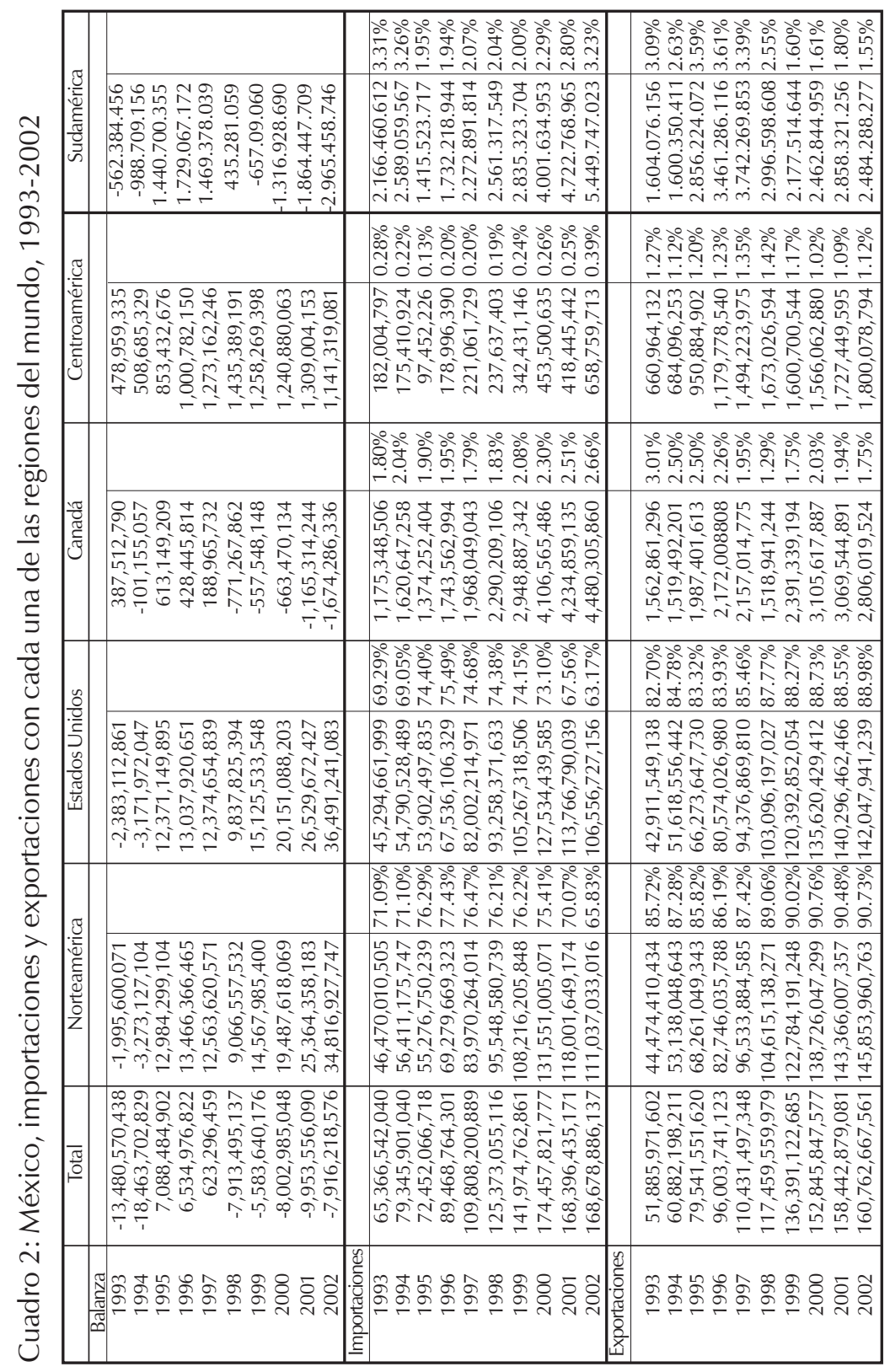




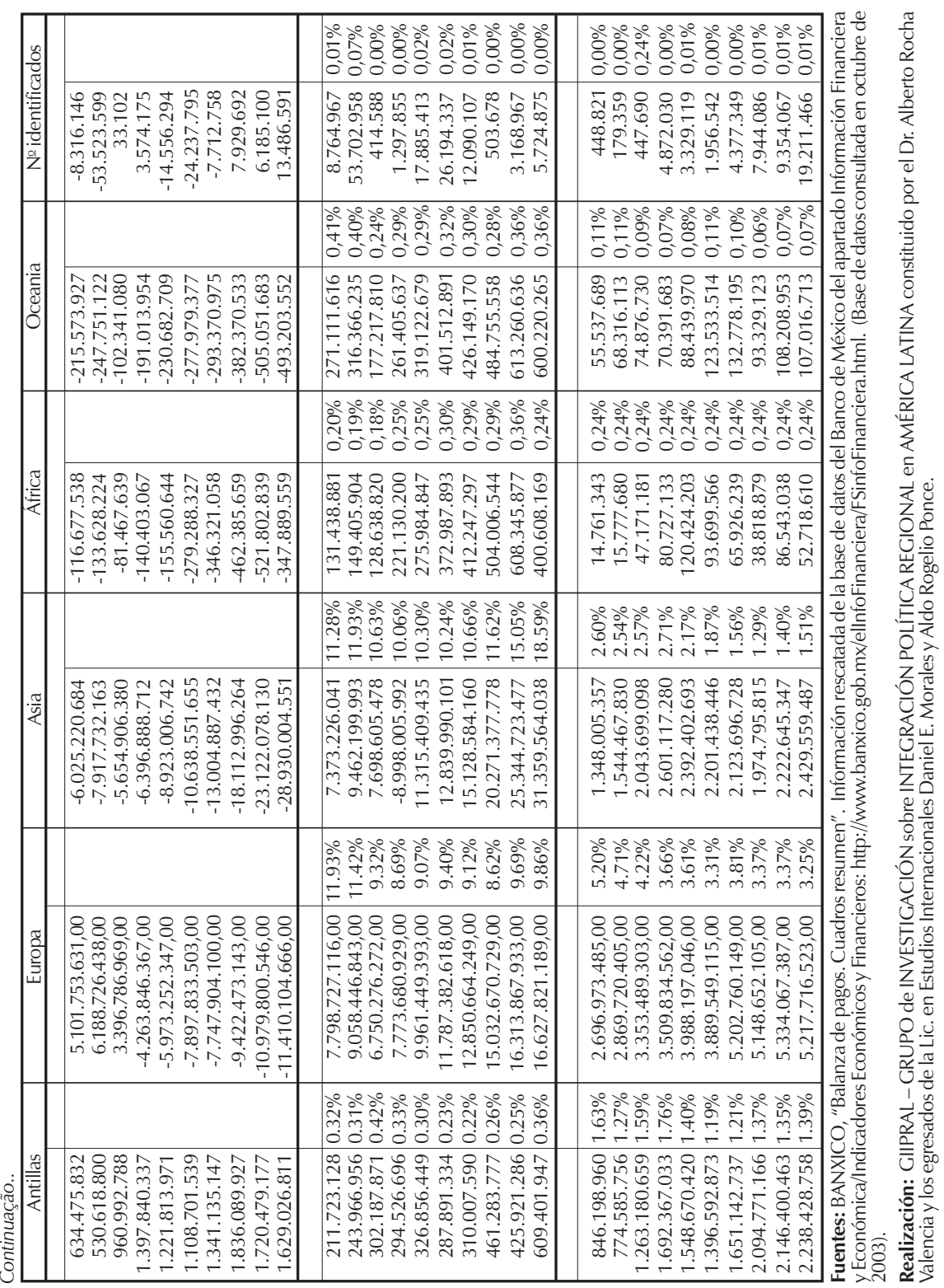


por la disminución de las importaciones con los EE.UU.; de 69.29\% a 63.17\%, en los años de 1993 y 2002 respectivamente. Después esta jerarquía se modifica sustantivamente con respecto a la anterior de las exportaciones. Asía se coloca en segundo lugar, seguida de Europa y de Sudamérica. Las Antillas, Centroamérica y Oceanía se nivelan en el quinto lugar. Y el sexto lugar es para África. ¿Qué sucede? Las importaciones mexicanas han emprendido una diversificación importante, para ello tuvieron que disminuir las importaciones procedentes de Norteamérica y, sobre todo, las procedentes de los EE.UU.; mientras que las importaciones con Canadá crecieron significativamente. Pero esta diversificación de las importaciones mexicanas se debe fundamentalmente al crecimiento sustantivo de las importaciones con Asia, a la conservación de la importaciones con Europa y a la mejora del comercio con las otras regiones.

En resumen, el cuadro que venimos de presentar y de analizar, nos permite reforzar las ideas de que el comercio de México se encuentra extremadamente relacionado con América del Norte y especialmente vinculado y concentrado con los EE.UU. Aquí vale la pena detenernos un momento para anotar una revelación importante. Los dos cuadros analizados revelan algo sumamente importante: No es tan importante cuánto comercie un país con los diversos países y regiones del mundo, pues lo que importa es la relación política que se puede establecer por medio del "COmercio" y de su herramienta privilegiada los TLC's. Algo más, los EE.UU. vienen haciendo uso extensivo de los TLC's como mecanismo excelso para redefinir su hegemonía en el mundo y en el continente americano. México hace uso de su comercio y de los TLC's para sentar su presencia en el mundo y reforzar su vocación mundial.

\section{Antecedentes de la relaciones geopolíticas y geoeconómicas México-Centroamérica}

Nos remontamos hasta los años setenta. Es conocido que durante los gobiernos de los presidentes Luis Echevarría y López Portillo, México inicio 
una política exterior activa con rasgos progresistas, nacionalistas, tercermundistas y latinoamericanistas. ${ }^{15}$ Pero de ellos dos, fue López Portillo (19761982) quién desplegó una política de mayor acercamiento y más solidaria con Centroamérica. Su gobierno apoyó la causa de los movimientos progresistas en El Salvador y en Nicaragua; además de apoyar la causa independentista de Belice. En el año de 1980 México y Venezuela firman el Acuerdo de San José, por medio del cual acuerdan suministrar petróleo y derivados a los países centroamericanos. Esta dinámica en la política exterior de México continúa con el gobierno del presidente Miguel de la Madrid (1982-1988). Ante el conflicto centroamericano (cuyos actores son los movimientos guerrilleros progresistas en Guatemala, Honduras y El Salvador; los gobiernos autoritarios en estos tres países; el gobierno sandinista de Nicaragua y, la intervención militar de los EE.UU.) México forma parte del Grupo de Contadora (1983), después del Grupo de los Ocho (1985) y apoya los acuerdos de la Cumbre de Esquipulas II (1987). También durante este gobierno se firmaron algunos convenios de cooperación económica con países como Nicaragua (1983), Costa Rica, Guatemala y Honduras (1984) y con El Salvador (1986).

\section{Proceso de institucionalización de la cooperación de México con Centroamérica}

Al finalizar el Gobierno de Miguel de la Madrid, en el año de 1987, en el contexto de reforma de la Constitución, se reconoce constitucionalmente la cooperación internacional. Este reconocimiento queda incorporado en el artículo 89, fracción décima, de la Constitución en tanto "cooperación internacional para el desarrollo". Desde entonces, se inicia un proceso de

15 Rafael Velásquez F., "El proyecto de política exterior de Vicente Fox: ¿Continuidad o cambio?", en La política exterior de México bajo un régimen democrático. ¿Cambio o continuidad?, op.cit. 
institucionalización de la cooperación mexicana con Centroamérica. Pero los pasos más importantes en esta dirección serán dados por los gobiernos que se sucederán en la alta función del poder ejecutivo. Así, durante el gobierno de Carlos Salinas (1988-1994) se crea la Comisión Mexicana para la Cooperación con Centroamérica (1990), un poco después se realiza la Primera Cumbre del Mecanismo de Diálogo y Concertación de TuxtlaGutiérrez (1991); seguidamente México se incorpora como socio extrarregional del Banco Centroamericano de Integración Económica (1992) y, finalmente, se decide proceder a una ampliación de la Comisión Mexicana para la Cooperación con Centroamérica hacia el Caribe (1994). Con el gobierno del presidente Ernesto Zedillo (1994-2000) se crea el Instituto Mexicano de Cooperación Internacional (1998), como un órgano desconcentrado de la Secretaría de Relaciones Exteriores e integrado por cuatro áreas: 1. Cooperación Técnica y Científica. 2. Cooperación Educativa y Cultural. 3. Cooperación Economía y de Desarrollo 4. Cooperación con Centroamérica y el Caribe. Desde este momento la Comisión Mexicana para la Cooperación es vinculada con la Dirección General para la Cooperación con Centroamérica y el Caribe del Instituto Mexicano de Cooperación Internacional y el Director Ejecutivo éste funge como Secretario Ejecutivo de la Comisión. La Comisión al momento de su fundación está integrada por 13 dependencias e entidades, las que pasaron a un número de 23 como resultado de la ampliación de funciones de la Comisión de Centroamérica hacia el Caribe. ${ }^{16}$

A inicios del gobierno del Presidente Vicente Fox, se emprende un proceso de reestructuración de la Secretaría de Relaciones Exteriores y del Instituto Mexicano de Cooperación Internacional. Ahora es la Subsecretaría de Relaciones Económicas y Cooperación Internacional, a través de la Dirección General de Cooperación Técnica y Científica, la encargada de

16 Consultar el documento "IMEXCI" $\mathrm{y}$ “Reglamento Interior de la Secretaría de Relaciones Exteriores”. (http://www.ser.gob.mx/ imexci/ ) 
"consolidar el Sistema Mexicano de Cooperación Internacional para el Desarrollo" y "fungir como Secretaría Técnica de la Comisión Mexicana para la Cooperación con Centroamérica". También la Coordinación General del Plan Puebla Panamá queda bajo la autoridad de esta Subsecretaría. ${ }^{17}$

\section{Campo de acción de las relaciones geopolíticas y geoeconómicas de México con Centroamérica}

El Estado mexicano construye su hegemonía regional con Centroamérica por medio del establecimiento de relaciones geopolíticas, geoeconómicas y de cooperación para el desarrollo. De estas tres formas de relaciones, las geopolíticas son las más importantes y priman sobre las otras. Para apoyar esta planteamiento citaré los trabajos de dos investigadores. El primero, Alfredo Guerra-Borges: "La iniciativa de crear una zona de libre comercio partió de México, cuyos intereses con Centroamérica no son tanto comerciales como geopolíticos".$^{18}$ El segundo, Daniel Villafuerte: "A México interesa Centroamérica porque más allá de las relaciones comerciales hay razones de geopolítica que están por encima de otras prioridades". ${ }^{19}$ Bien, es cierto que a México le interesa el desarrollo de Centroamérica, pero se han levantado algunas preguntas al respecto. Si se ensaya una respuesta, esta es que no son tanto las cuestiones económico-comerciales y de desarrollo las que le importan, sino más bien las cuestiones políticas y geopolíticas; es decir, los temas económico-comerciales y del desarrollo interesan porque permiten alcanzar otros objetivos importantes. Estos otros

\footnotetext{
17 Consultar documento "Reglamento Interior de la Secretaría de Relaciones Exteriores", publicado en el Diario Oficial de la Federación el 10 de agosto de 2001. Este documento fue modificado mediante Decretos en octubre de 2001, julio de 2002, agosto de 2002 y noviembre de 2002. (http://www.ser.gob.mx/acerca/normatividad/reglamento.htm )

18 Alfredo Guerra-Borges: La integración centroamericana ante el reto de la globalización (antología), CRIES, Managua, 1996. Página: 58.

19 Daniel Villafuerte Solís: Integraciones comerciales en la frontera sur. Chiapas frente al Tratado de Libre Comercio MéxicoCentroamérica, UNAM/PRIMMSE, México, 2001, p. 305.
} 
objetivos se relacionan con los intereses geopolíticos de México (el subhegemón) y con los intereses geopolíticos de los EE.UU. (que trata de resurgir como hegemón), todo lo cual conduce a los intereses geopolíticos de un macrosistema de integración regional como el TLCAN.

El campo de las relaciones de México con Centroamérica dispone de un marco institucional muy preciso como El Mecanismo de Diálogo y Concertación de Tuxtla-Gutiérrez, y sus cuatro ámbitos de acción muy bien definidos: 1. Ámbito político y geopolítico. 2. Ámbito del desarrollo. 3. Ámbito de la cooperación técnica regional. 4. Ámbito económico, comercial y financiero. $\mathrm{Y}$ en cada uno de estos cuatro ámbitos se dispone de herramientas respectivas para su impulso: 1. Las Cumbres de Tuxtla. 2. El Plan Puebla Panamá. 3. La Comisión Mexicana para la Cooperación con Centroamérica y la Secretaría General del SICA. 4. Los TLC's. Todo este marco institucional puede apreciarse en el Diagrama: Campo de las relaciones geopolíticas y geoeconómicas de México con Centroamérica (ver figura 3) que presentamos en seguida.

Ámbito político y geopolítico

Este ámbito de acción es impulsado por medio de las Cumbres de Tuxtla. Hasta el momento se han realizado seis Cumbres, cinco ordinarias y una extraordinaria, entre los años de 1991 y 2002. Está prevista para el 2004 la Cumbre de Tuxtla VI. La Cumbre de Tuxtla I (México, 1991) fue la cumbre fundacional. En esta cumbre participan México y cinco países centroamericanos (no están presentes Belice y Panamá). De parte de Méxi$\mathrm{CO}$, se hace conocer la creación reciente de la Comisión Mexicana para la Cooperación con Centroamérica y se presenta la Política Mexicana de Cooperación con Centroamérica. Además se suscriben las bases de un acuerdo de cooperación económica que debería conducir hacia la conformación de un área de libre comercio. En este evento se festeja el 
Diagrama - Campo de las relaciones geopolíticas y geoeconómicas de México con Centroamérica (Figura 3)

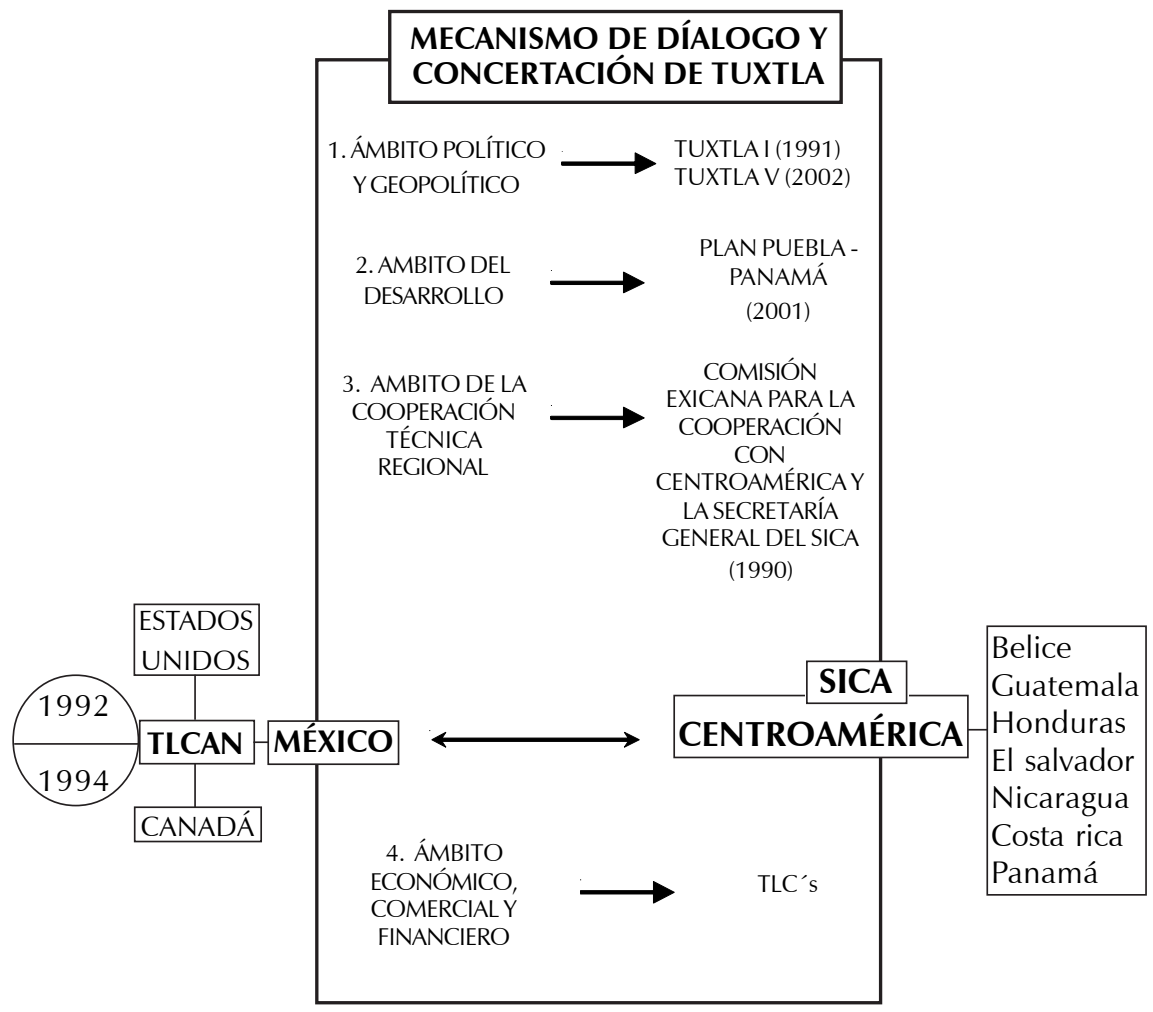

REALIZACIÓN:

GIIPRAL - GRUPO de INVESTIGACIÓN sobre INTEGRACIÓN POLÍTICA REGIONAL en AMÉRICA LATINA; constituido por el Dr. Alberto Rocha Valencia y los Egresados de la Lic. en Estudios Internacionales: Daniel E. Morales y Aldo Ponce Margarito 
lanzamiento de la Iniciativa de las Américas por el presidente de los EE.UU. de ese entonces, George Bush (padre). Esta cumbre marca un primer hito. ${ }^{20}$

El segundo hito tuvo que esperar para concretarse. La Cumbre de Tuxtla II (Costa Rica, 1996) se realizó después de cinco años y, solamente, se logró concretar después de que tuvieran lugar algunos acontecimientos importantes. En efecto, durante esos años se firma y entra en vigencia el TLCAN (1991 y 1994, respectivamente), también se firma y entra en vigencia el G-3 (1994 y 1995, respectivamente) y se celebra la Primera Cumbre de las Américas (1994). Tuxtla II tuvo que esperar que México se incorporara como el tercer socio del TLCAN, que México buscara establecer un buen referente en Sudamérica (Colombia y Venezuela) y que finalmente México (junto con todos los países centroamericanos) se haya incorporado al Proceso de Cumbres de las Américas. Tuxtla II sirvió para concretar el Mecanismo de Diálogo y Concertación entre México y Centroamérica (ahora presentes los siete países), cuya institucionalidad queda integrada de la siguiente manera: Cumbre presidencial, Reunión de Cancilleres, Comisión de Alto Nivel y Subcomisiones (de Asuntos Políticos, de Asuntos Económicos, Comerciales y Financieros, y de Cooperación Regional). En esta cumbre se aprueba un Plan de Acción cuyos componentes son: Asuntos políticos, Asuntos económicos, comerciales y financieros, y Asuntos de Cooperación regional. Además, México se integra como socio extrarregional del Banco Centroamericano de Integración Económica. Esta cumbre es muy importante porque es una de relanzamiento y de fortalecimiento de las relaciones entre México y Centroamérica; su realización permitió diseñar un marco institucional para las interacciones permanentes entre los gobiernos de ambas partes, además que ayudó a precisar los dominios de acción de dichas interacciones. ${ }^{21}$

\footnotetext{
20 Cumbre de Tuxtla I: Declaración de Tuxtla Gutiérrez, Tuxtla Gutiérrez-Chiapas, México, 10 y 11 de enero de 1991. (http:// www.sgsica.org/reuniondepresidentes/documentos/declara-tuxtla-l.html)

21 Cumbre de Tuxtla II: Declaración Conjunta y Plan de Acción de la reunión de Jefes de Estado y de Gobierno de Centroamérica y de México, San José, Costa Rica, 15 y 16 de febrero de 1996. (http://www.sgsica.org/reuniondepresidentes/documentos/ declara-tuxtla-II.html)
} 
Tuxtla III (El Salvador, 1998) se realizó en la fecha prevista, pues se había acordado que estas cumbres tendrían lugar cada dos años. Mientras tanto, ya se habían firmado los TLC's México-Costa Rica y México-Nicaragua. En esta cumbre se impulsan los proyectos de dos TLC's más, México-Triángulo del Norte (Guatemala, Honduras y El Salvador) y México-Panamá. También se acuerda profundizar la cooperación económica y se aprueba el Programa de Cooperación Regional México-Centroamérica (1998-2000) con sus seis áreas prioritarias (educación y cultura, medio ambiente, salud, turismo, agricultura y ganadería, prevención y atención de desastres). En esta cumbre se designa a la Secretaría General del SICA como contraparte de la Comisión Mexicana para la Cooperación con Centroamérica. ${ }^{22}$ En Tuxtla IV (Guatemala, 2000), se introducen por primera vez las ideas de "Región Mesoamericana" y de "Comunidad Mesoamericana de Naciones". Así, desde estos momentos, son emplazadas las ideas fuerza de la vinculación geopolítica de México con Centroamérica. Estas ideas fuerza, por el consenso que reciben de las partes y por la identificación que generan en las partes, son fundadoras de una hegemonía regional. "Mesoamérica" es un espacio regional común y compartido; además de un espacio regional de tradiciones comunes, de culturas indígenas vivas y de pueblos indígenas emergentes. "Mesoamérica" es una región binacional y transfornteriza, donde se conjugan pueblos y naciones de una comunidad posible. "Mesoamérica" es una realidad regional con problemas comunes de pobreza y subdesarrollo. En fin, en esta cumbre se celebra la incorporación del Congreso de México como observador del PARLACEN (Parlamento Centroamericano); se respalda la firma del TLC México-TN y se siguen apoyando las negociaciones para un TLC México-Panamá; y se aprueba el Programa de Cooperación Regional MéxicoCentroamérica (2001-2002). ${ }^{23}$

22 Cumbre de Tuxtla III: Declaración Conjunta de los Jefes de Estado y de Gobierno de los Países integrantes del Mecanismo de Diálogo y Concertación de Tuxtla, San Salvador, El Salvador, 17 de junio de 1998. (http://www.sgsica.org/reuniondepresidentes/ documentos/declara-tuxtla-III.html)

23 Cumbre de Tuxtla IV: Declaración Conjunta de los Jefes de Estado y de Gobierno de los Países integrantes del Mecanismo de Diálogo y de Concertación de Tuxtla, Ciudad de Guatemala, Guatemala, 25 de agosto de 2000. (http://www.sgsica.org/ reuniondepresidentes/documentos/declara-tuxtla-IV.html) 
Al año siguiente de Tuxtla IV, por iniciativa del Presidente Vicente Fox, se organizó una Cumbre Extraordinaria de Tuxtla (El Salvador, 2001) con la finalidad de concretar y lanzar el Plan Puebla Panamá. Este PPP estará destinado a convertirse en herramienta clave del Ámbito del Desarrollo. ${ }^{24}$ Finalmente en Tuxtla V (México, 2002) se acuerda consolidar la "Comunidad Mesoamericana de Naciones" y la "integración mesoamericana"; y se decide fortalecer el Mecanismo de Diálogo y Concertación de Tuxtla-Gutiérrez. También se aprueba el Programa de Cooperación Regional MéxicoCentroamérica (2003-2004). ${ }^{25}$

La Cumbre de Tuxtla, como mecanismo de diálogo y concertación de un grupo de Jefes Gobiernos y de Estados (grupo formado según la fórmula $1+7$ ), es a toda vista un foro donde las iniciativas políticas del Estado mexicano convocan e interpelan las iniciativas de los siete Estados centroamericanos; un foro donde las iniciativas de siete gobiernos se acuerdan con las de un gobierno; es un foro donde las proyecciones geopolíticas de un Estado priman sobre las proyecciones geopolíticas de los otros siete Estados. En fin, este foro político, cargado de geopolítica, es uno donde va tomando forma una hegemonía regional o una subhegemonía.

Ámbito del desarrollo

El Plan Puebla-Panamá se comenzó a elaborar durante el Gobierno del Presidente Ernesto Zedillo, pero fue con el Gobierno del Presidente Vicente Fox que se le terminó de dar forma. Es así como el mismo Presidente Vicente Fox se encarga de lanzar la iniciativa del PPP, el 11 de marzo de 2001. El PPP que se aprueba en la Cumbre Extraordinaria de Tuxtla es el resultado de la fusión de dos estrategias: 1. La estrategia de desarrollo para el Sur-Sureste de México (12 de marzo de 2001). ${ }^{26}$ 2. La estrategia para la 
transformación y modernización de Centroamérica para el Siglo XXI (8 de marzo de 2001). Este PPP, síntesis de las dos estrategias, quedó explicitado por un objetivo general e integrado por ocho Iniciativas Mesoamericanas, cada una con sus respectivos objetivos específicos. (Esquema, Plan PueblaPanamá: Iniciativas mesoamericanas y objetivos, ver figura 4)

ESQUEMA - Plan Puebla - PANAMÁ: iniciativas mesoamericanas y objetivos (Figura 4)

El objetivo general del Plan Puebla-Panamá es potenciar la riqueza humana y ecológica de la Región Mesoamericana, dentro de un marco de desarrollo sustentable que respete la diversidad cultural y étnica. Por ello, se plantea una estrategia integral para la región que ampara un conjunto de iniciativas y proyectos mesoamericanos.

\begin{tabular}{|c|c|}
\hline INICIATIVAS & OBJETIVOS \\
\hline $\begin{array}{l}\text { Iniciativa Mesoamericana } \\
\text { de Desarrollo Sustentable }\end{array}$ & $\begin{array}{l}\text { promover la conservación y el manejo sustentable de los } \\
\text { recursos naturales y los mecanismos participativos, especial- } \\
\text { mente de las comunidades locales, en la gestión ambiental }\end{array}$ \\
\hline $\begin{array}{l}\text { Iniciativa Mesoamericana } \\
\text { de Desarrollo Humano }\end{array}$ & $\begin{array}{l}\text { reducir la pobreza, facilitar el acceso a los servicios sociales } \\
\text { básicos de la población vulnerable y contribuir al pleno } \\
\text { desarrollo de los pueblos mesoamericanos }\end{array}$ \\
\hline $\begin{array}{l}\text { Iniciativa Mesoamericana de } \\
\text { Prevención y Mitigación de } \\
\text { Desastres Naturales }\end{array}$ & $\begin{array}{l}\text { promover la prevención y mitigación de desastres naturales } \\
\text { e incorporar la consideración de la gestión del riesgo en los } \\
\text { proyectos de todos los sectores }\end{array}$ \\
\hline $\begin{array}{l}\text { Iniciativa Mesoamericana de } \\
\text { Promoción del Turismo }\end{array}$ & $\begin{array}{l}\text { promover el desarrollo del turismo ecológico, cultural e } \\
\text { histórico mediante acciones regionales que destaquen la } \\
\text { complementariedad, las economías de escala y los } \\
\text { encadenamientos productivos del turismo }\end{array}$ \\
\hline $\begin{array}{l}\text { Iniciativa Mesoamericana de } \\
\text { Facilitación del Intercambio Comercial }\end{array}$ & $\begin{array}{l}\text { fomentar el intercambio comercial en la región mediante } \\
\text { una reducción de los costos de transacción en el comercio } \\
\text { entre los países y promover la participación de pequeñas y } \\
\text { medianas empresas en las exportaciones regionales }\end{array}$ \\
\hline $\begin{array}{l}\text { Iniciativa Mesoamericana de } \\
\text { Integración Vial }\end{array}$ & $\begin{array}{l}\text { promover la integración física de la región para facilitar el } \\
\text { tránsito de personas y mercancías y, de esta manera, reducir } \\
\text { los costos de transporte }\end{array}$ \\
\hline $\begin{array}{l}\text { Iniciativa Mesoamericana de } \\
\text { Interconexión Energética }\end{array}$ & $\begin{array}{l}\text { unificar e interconectar los mercados eléctricos con miras a } \\
\text { promover un aumento de las inversiones en el sector y una } \\
\text { reducción del precio de la electricidad }\end{array}$ \\
\hline $\begin{array}{l}\text { Iniciativa Mesoamericana de Integración } \\
\text { de los Servicios de Telecomunicaciones }\end{array}$ & $\begin{array}{l}\text { desarrollar la infraestructura de interconexión informática } \\
\text { de la región }\end{array}$ \\
\hline
\end{tabular}

Fuente: Plan Puebla-Panamá. Iniciativas Mesoamericanas y Proyectos. Grupo Técnico Interinstitucional para el Plan Puebla-Panamá, BCIE-BID-CEPAL con el apoyo del INCAE. San Salvador, El Salvador. 15 de Junio de 2001.

Realización: GIIPRAL - GRUPO de INVESTIGACIÓN sobre INTEGRACIÓN POLÍTICA REGIONAL en AMÉRICA LATINA; constituido por el Dr. Alberto Rocha Valencia y los egresados del Dep. de Estudios Internacionales: Daniel Morales Ruvalcaba y Aldo Ponce Margarito. 
En términos generales, el PPP es un megaproyecto diseñado para impulsar el desarrollo de una Región llamada Mesoamérica, entendida esta como un espacio formado por la vinculación entre el Sursureste de México (Estados de Puebla, Guerrero, Veracruz, Oaxaca, Campeche, Quintana Roo, Tabasco, Yucatán y Chiapas) y los siete Estados de Centroamérica. ${ }^{27}$

Para la buena implementación del PPP fue necesario establecer un esquema institucional muy funcional, donde una Comisión Ejecutiva se encarga de la gestión general y cada uno de los ocho países se hace responsable de la realización y gestión de cada una de las ocho Iniciativas Mesoamericanas. (Organigrama, Estructura Institucional del Plan PueblaPanamá, ver figura 5).

La realización de las Iniciativas Mesoamericanas implicó diseñar proyectos específicos para cada una de ellas y buscar fuentes de financiamiento. Según los proyectos y la inversión total proyectada para su ejecución (hasta junio de 2002), las Iniciativas Mesoamericanas se pueden organizar en el orden de importancia siguiente: Primer lugar, Turismo; segundo lugar, integración vial; tercer lugar, desarrollo sostenible; cuarto lugar, interconexión energética; quinto lugar, servicios de telecomunicaciones; sexto lugar, desarrollo humano; séptimo lugar, prevención y mitigación de desastres naturales; $y$, octavo lugar, facilitación del intercambio comercial y aumento de la competitividad. (Cuadro, Plan Puebla Panamá: Iniciativas Mesoamericanas y Proyectos, ver figura 6).

En resumen, el PPP es un megaproyecto que abarca ocho iniciativas, veintinueve proyectos, un número importante de instituciones internacionales y de países y gran cantidad de recursos financieros. Además, se ha incluido un Programa de Información, Consulta y Participación que se propone involucrar a las organizaciones de la sociedad civil y a las comunidades de base. Todo esto seguramente es lo que ha contribuido a levantar

27 Consultar Cumbre Extraordinaria de Tuxtla: Declaración conjunta de los Jefes de Estado y de Gobierno de los Países integrantes del Mecanismo de Diálogo y Concertación de Tuxtla, San Salvador, El Salvador, 15 de mayo de 2001. (http://www.sgsica.org/ reuniondepresidentes/documentos/declara-ca-tuxtla.html) ; Carlos Orellana Merlos: Plan Puebla-Panamá, Boletín No 193 (http://www.fusades.com.sv/investigacion_economica/decs/documentos/bol193.pdf ) 
Sociologias, Porto Alegre, ano 8, no 16, jul/dez 2006, p. 308-359

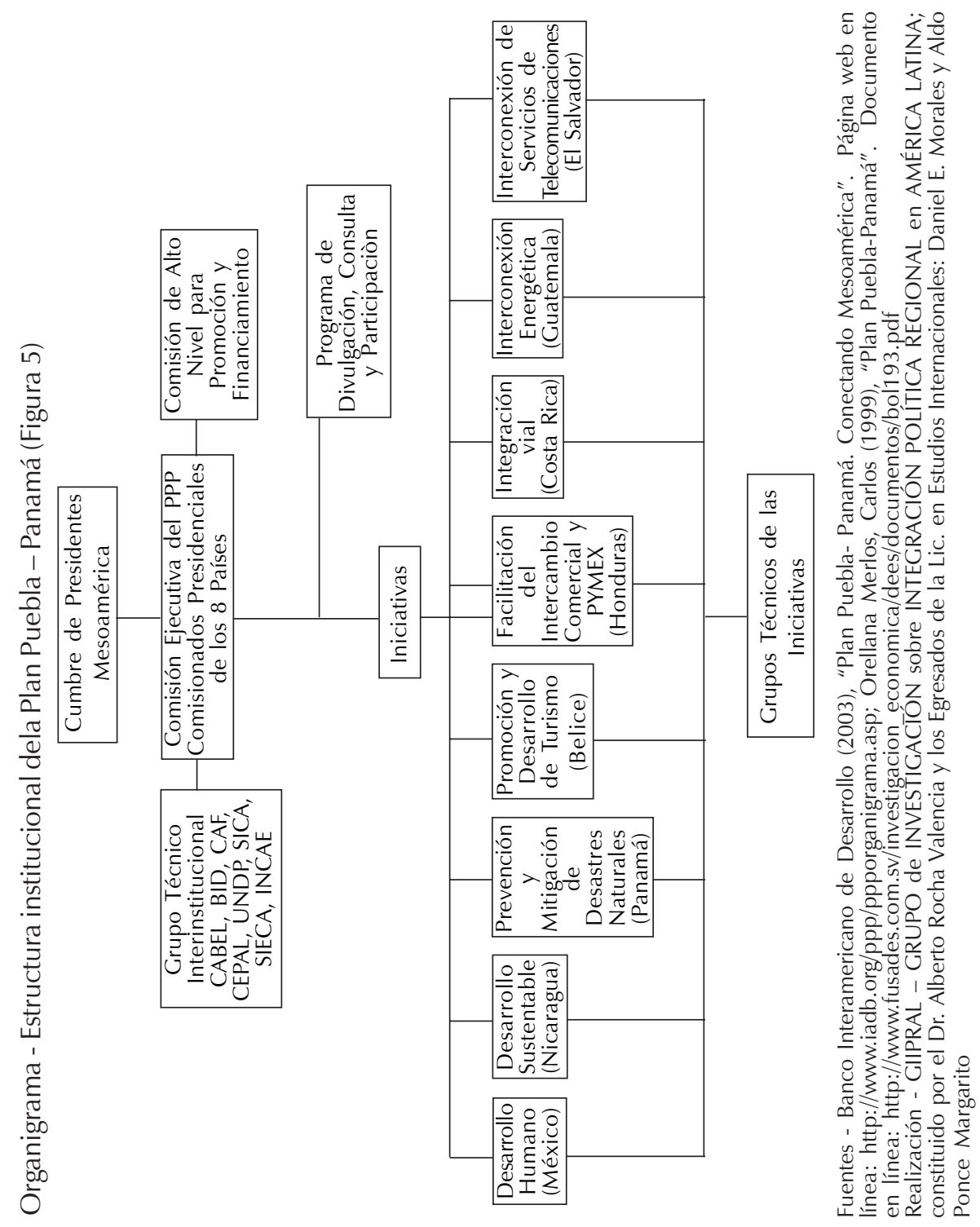


Sociologias, Porto Alegre, ano 8, no 16, jul/dez 2006, p. 308-359

\begin{tabular}{|c|c|c|c|c|c|}
\hline 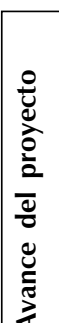 & 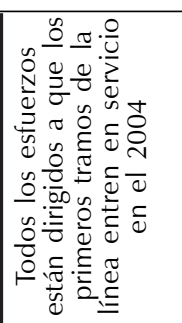 & 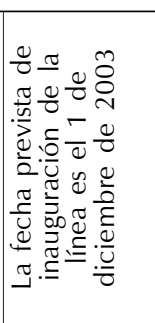 & 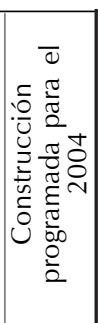 & 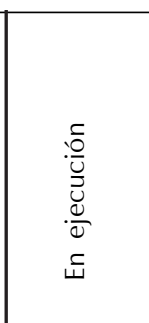 & 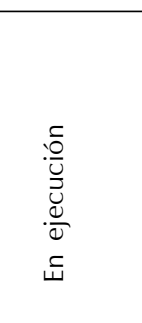 \\
\hline 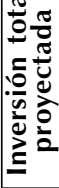 & 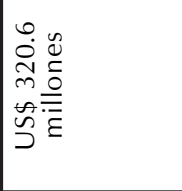 & 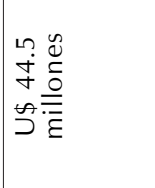 & 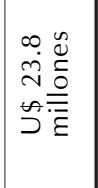 & 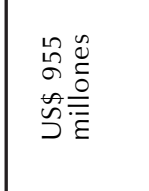 & 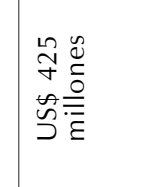 \\
\hline 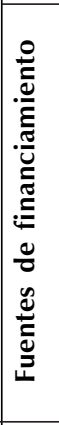 & 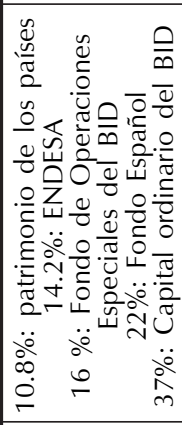 & 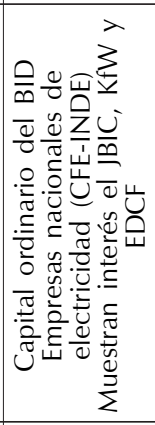 & & 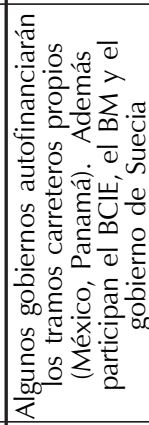 & 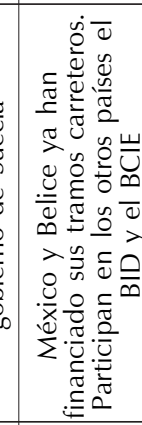 \\
\hline 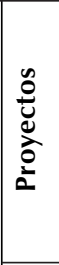 & 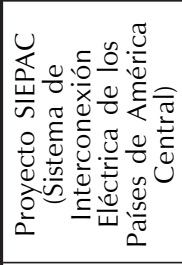 & 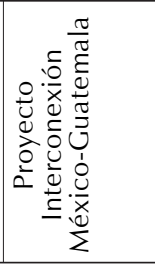 & 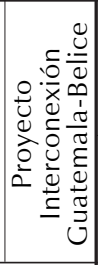 & 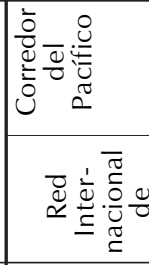 & 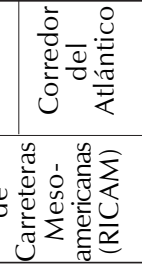 \\
\hline 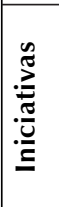 & 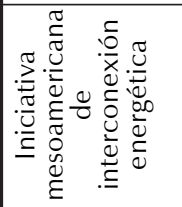 & 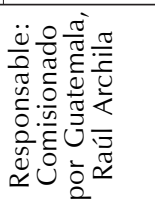 & & 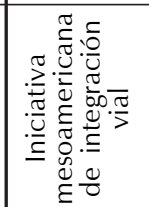 & 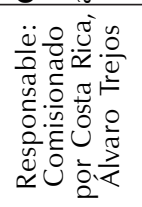 \\
\hline
\end{tabular}




\begin{tabular}{|c|c|c|c|}
\hline 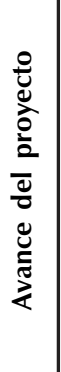 & 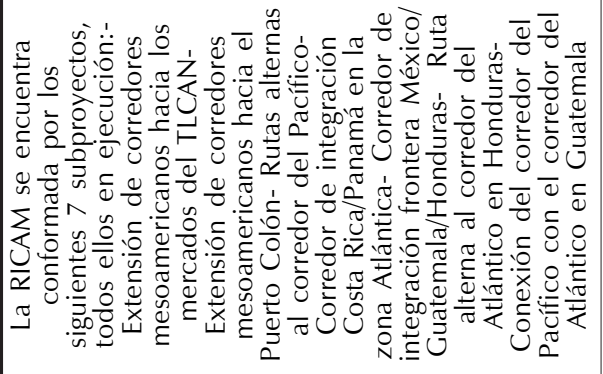 & 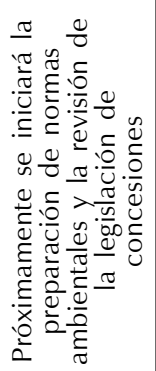 & 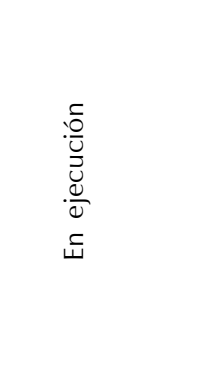 \\
\hline 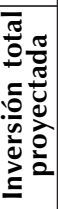 & 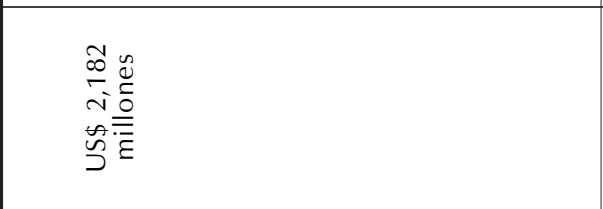 & 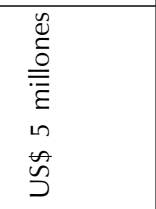 & 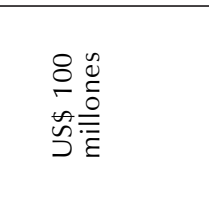 \\
\hline 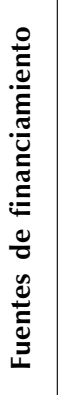 & 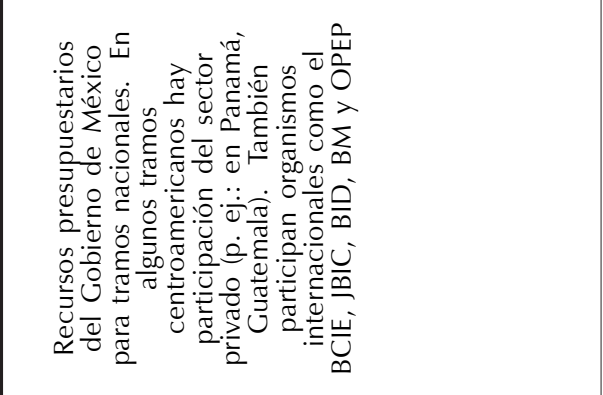 & 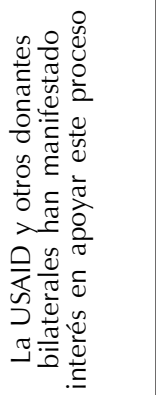 & 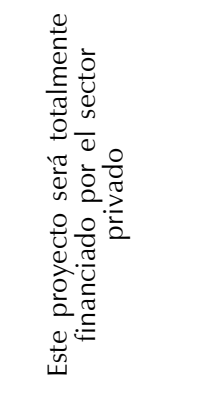 \\
\hline 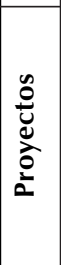 & 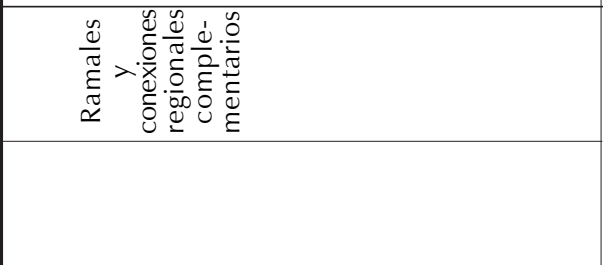 & 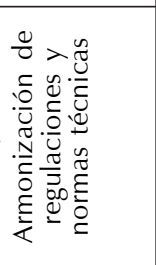 & 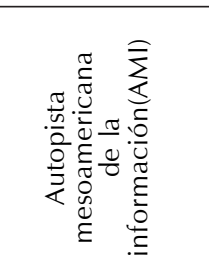 \\
\hline 胥 & 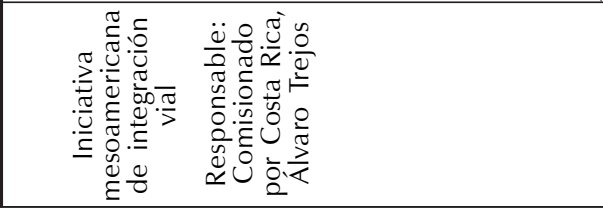 & & 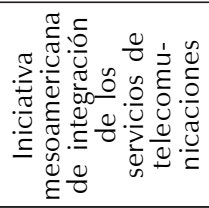 \\
\hline
\end{tabular}


Sociologias, Porto Alegre, ano 8, no 16, jul/dez 2006, p. 308-359

\begin{tabular}{|c|c|c|c|c|c|c|c|c|c|}
\hline 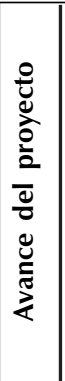 & 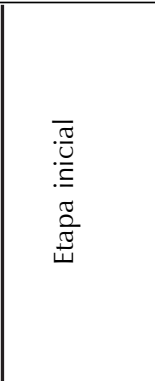 & 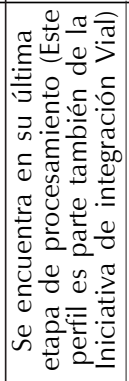 & 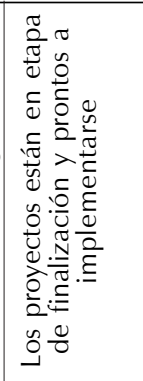 & 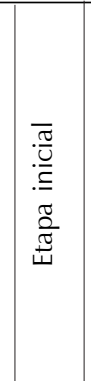 & 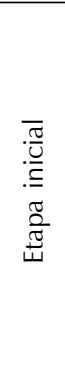 & 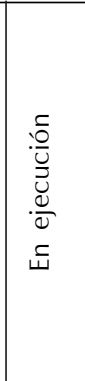 & 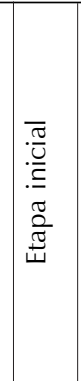 & & 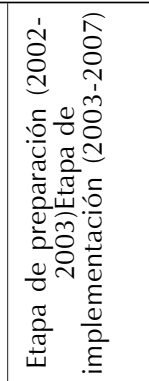 \\
\hline 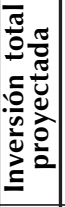 & 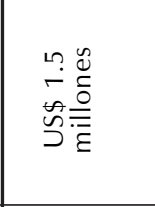 & 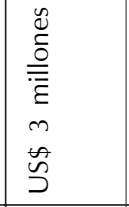 & 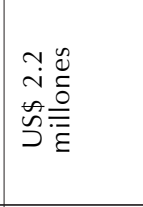 & 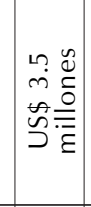 & 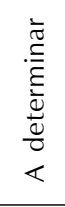 & 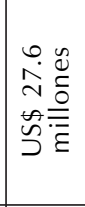 & 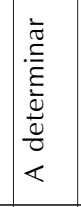 & 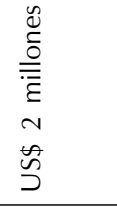 & 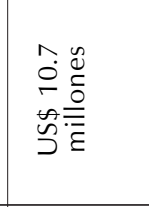 \\
\hline 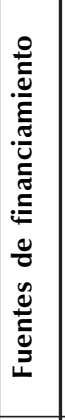 & 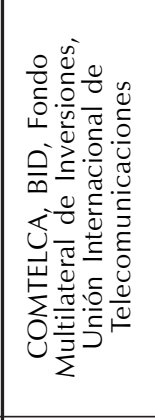 & 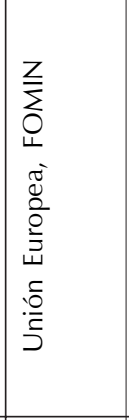 & 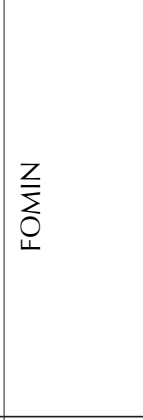 & 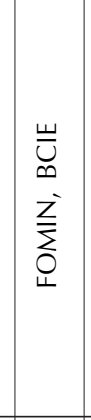 & $\stackrel{\emptyset}{\infty}$ & 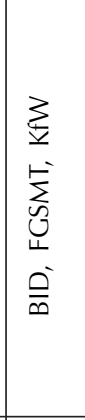 & 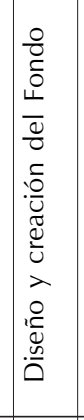 & 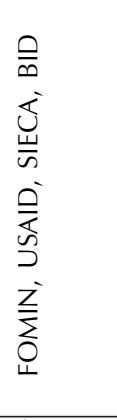 & 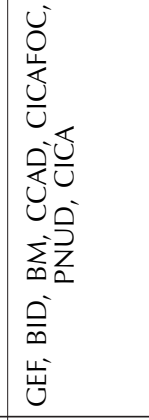 \\
\hline 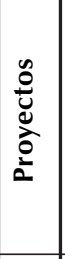 & 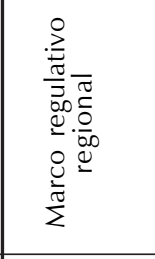 & 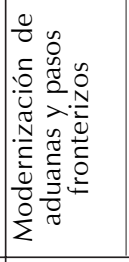 & 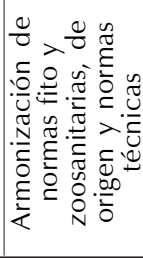 & 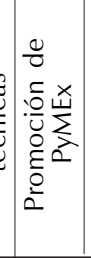 & 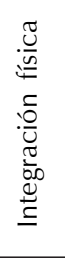 & 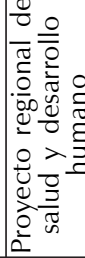 & 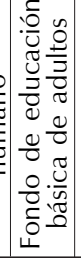 & 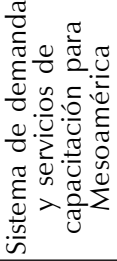 & 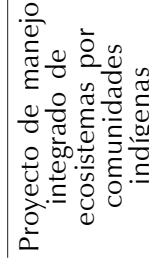 \\
\hline 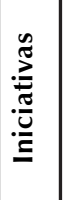 & 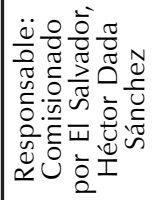 & \multicolumn{4}{|c|}{ 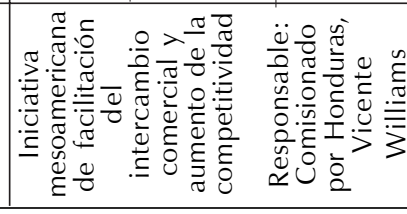 } & \multicolumn{4}{|c|}{ 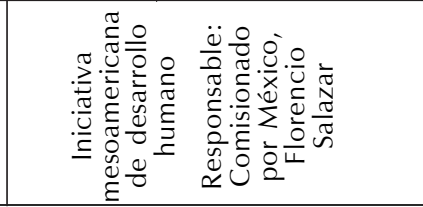 } \\
\hline
\end{tabular}


Sociologias, Porto Alegre, ano 8, no 16, jul/dez 2006, p. 308-359

\begin{tabular}{|c|c|c|c|c|c|}
\hline 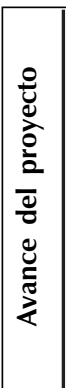 & & 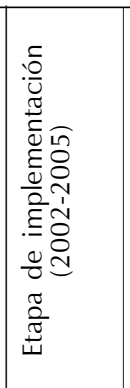 & 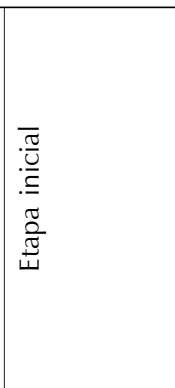 & 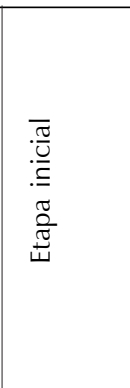 & 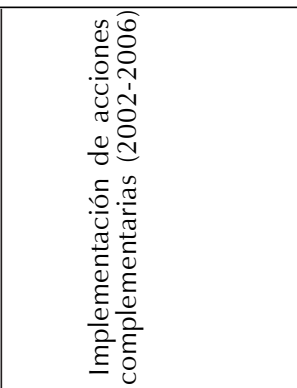 \\
\hline 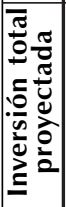 & 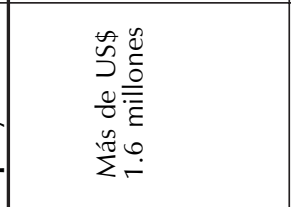 & 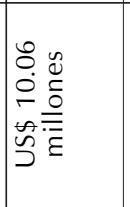 & 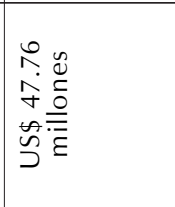 & 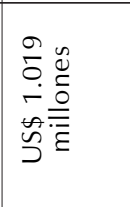 & 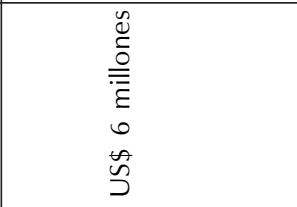 \\
\hline 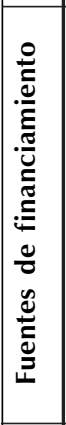 & 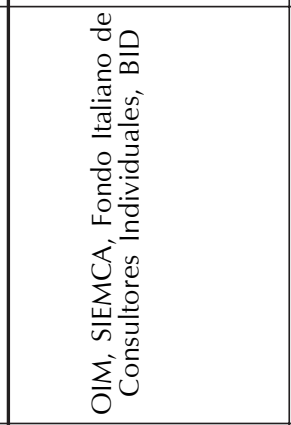 & 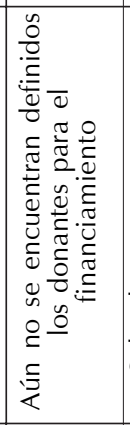 & 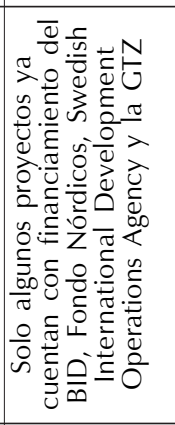 & 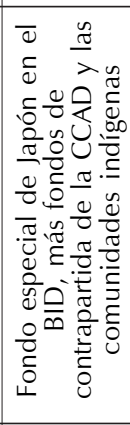 & 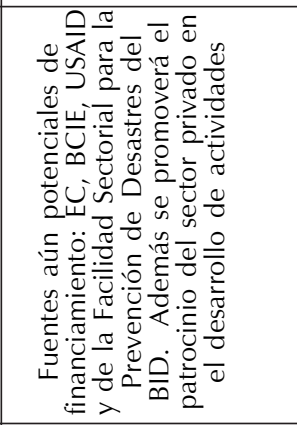 \\
\hline & 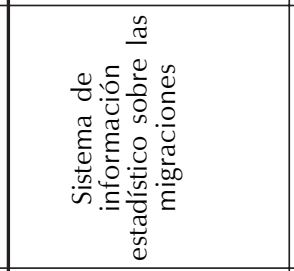 & 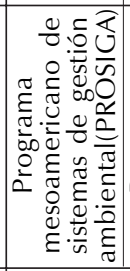 & 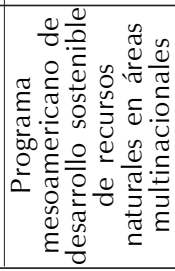 & 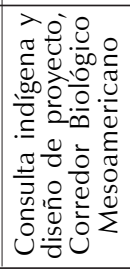 & 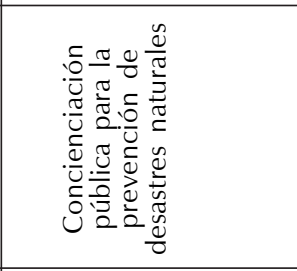 \\
\hline 竞 & 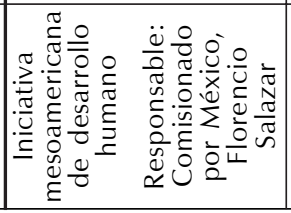 & 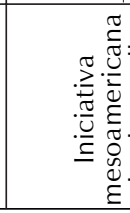 & 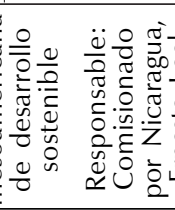 & & 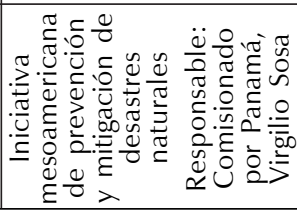 \\
\hline
\end{tabular}


Sociologias, Porto Alegre, ano 8, no 16, jul/dez 2006, p. 308-359

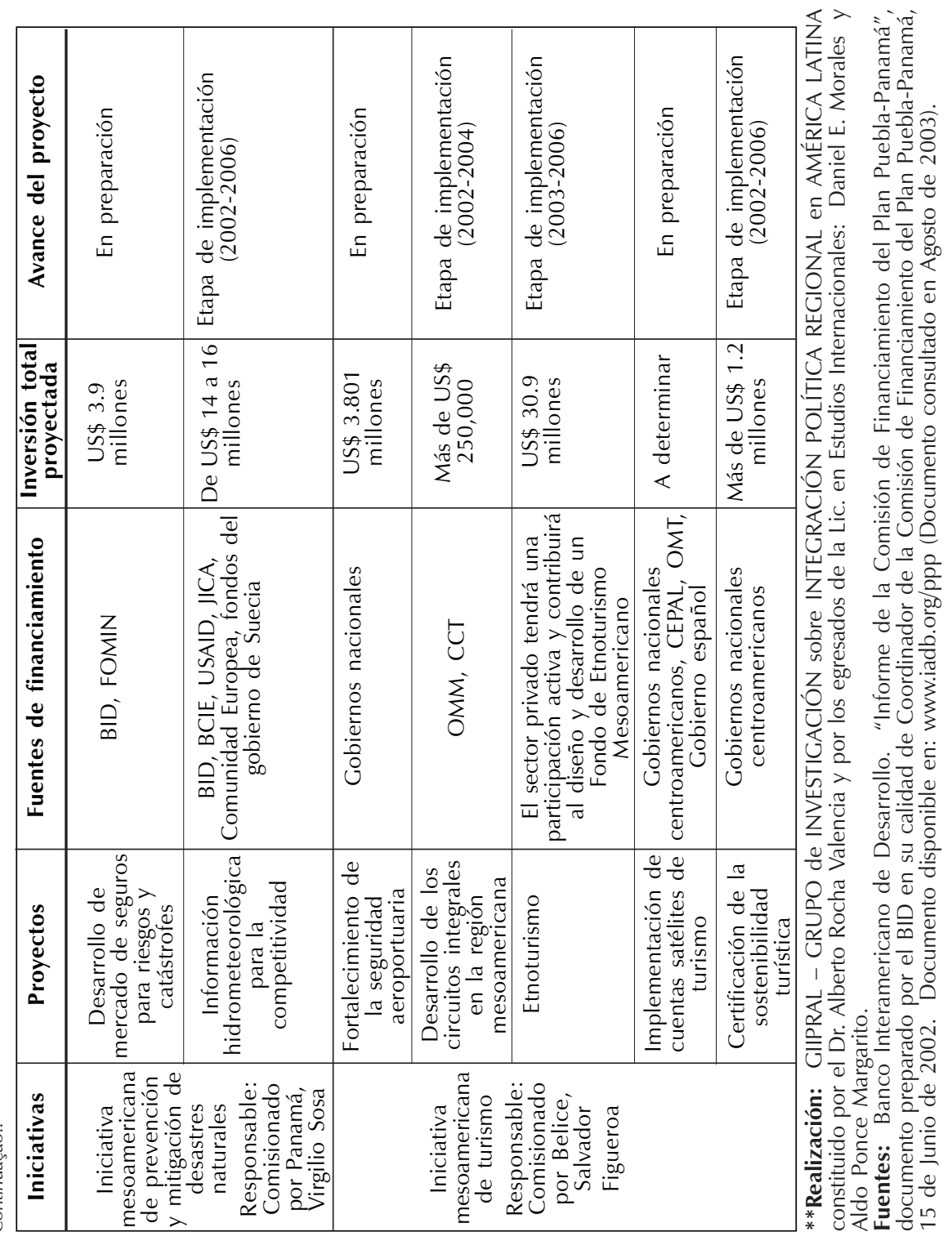


sospechas e interrogantes en los diversos sectores y actores de la sociedad civil centroamericana, mesoamericana, mexicana y más allá. Tenemos que decirlo, se ha puesto mucha ideología en circulación respecto del PPP, cuando más bien era necesario emprender y difundir análisis académicos serenos y serios. Aquí, solamente haremos algunas anotaciones más sobre cuestiones que aparecen muy explícitas en el cuadro que acabamos de presentar. Estas consideraciones son: 1. El PPP dispone de una vocación internacional explícita. 2. El PPP es una herramienta de geopolítica regional, pues está propiciando la vinculación e integración de Centroamérica con México (a través de la región "nexo" Sur-Sureste). 3. El PPP es una herramienta de geopolítica continental, porque está favoreciendo la vinculación e integración de

\section{**Continuação...}

Siglas y abreviaciones:

BCIE- Banco Centroamericano de Integración Económica BID- Banco Interamericano de Desarrollo

BM- Banco Mundial

CCAD- Comisión Centroamericana de Ambiente y Desarrollo

CCT-Comité Centroamericano de Turismo

CEPAL- Comisión Económica para América Latina y el Caribe

CFE- Comisión Federal de Electricidad (México)

CICA- Consejo Indígena de Centroamérica

CICAFOC-Coordinadora Indígena Campesina de Agroforestería Comunitaria

COMTELCA- Comisión Técnica Regional de Telecomunicaciones

EC-Comisión Europea

EDCF- Economic Development Cooperation Fund (Corea)

FGSMT- Fondo Global de Lucha contra el VIH/SIDA, malaria y tuberculosis

FOMIN- Fondo multilateral de inversiones

GEF- Fondo para el Medio Ambiente Mundial

GTZ- - Gesellschaft für Technische Zusammenarbeit (Alemania)

INDE- Instituto Nacional de Electrificación (Guatemala)

JBIC- Banco de Japón para la Cooperación Internacional (Japón)

JICA- Agencia Japonesa para la Cooperación Internacional (Japón)

KfW- Kreditanstaldt fur Wiederaurfbau (Alemania)

PNUD- Programa de Naciones Unidas para el Medio Ambiente

OMM- Organización del Mundo Maya

OMT- Organización Mundial de Turismo

OPEP-Organización de Países Exportadores de Petróleo

SIECA- Sistema de Integración Económica Centroamericana

USAID- Agencia para el Desarrollo Internacional de los Estados Unidos (Estados Unidos) 
Centroamérica con EE.UU. (a través de la función "nexo" de México) 4. El PPP es una herramienta de geopolítica continental, porque está promoviendo la vinculación e integración de Centroamérica con el TLCAN. Desde nuestros análisis estas son las cuestiones de fondo que están contenidas en el PPP. Ámbito de la cooperación técnica regional

En el punto siete de este trabajo hemos avanzado algunos desarrollos sobre la cooperación técnica regional que despliega México para Centroamérica. En ese apartado nos hemos ocupado del proceso de institucionalización de dicha cooperación. Ahora avancemos unos desarrollos más. La Comisión Mexicana de Cooperación con Centroamérica (CMCC) dispone de una Política de Cooperación con Centroamérica, la que se desenvuelve en tres dominios: 1. Económico. 2. Educativo-cultural. 3. Técnico-científico. A la vez, cada uno de estos dominios aborda diversos rubros. (Esquema: Ámbito de la cooperación técnica-regional, ver figura 7).

Para mayor información, aunque limitada a los años de 1991-1996, presentaremos tres cuadros con el número de proyectos ejecutados en cada uno de los tres dominios de la cooperación de México con Centroamérica. En el dominio económico y financiero, Centroamérica se benefició con 387 proyectos: la subregión entera se benefició con 34 proyectos y países como Costa Rica, El Salvador, Guatemala y Honduras resultaron los más favorecidos. Para el año de 1996, estás cifras declinan radicalmente. En el dominio educativo y cultural, Centroamérica fue receptora de 1,808 proyectos: para la región se dedicaron 162 proyectos y países como Costa Rica, El Salvador, Guatemala y Belice fueron los más auxiliados. En el dominio técnico y científico, Centroamérica acogió 2,340 proyectos; la región sola concentro 104 proyectos y países como Guatemala, Nicaragua, El Salvador y Costa Rica fueron los más apoyados. (Cuadros: Cooperación económica y financiera de México con Centroamérica; Cooperación educativa y cultural de México con Centroamérica; Cooperación técnica y científica de México con Centroamérica, ver figura 8). 
Sociologias, Porto Alegre, ano 8, no 16, jul/dez 2006, p. 308-359

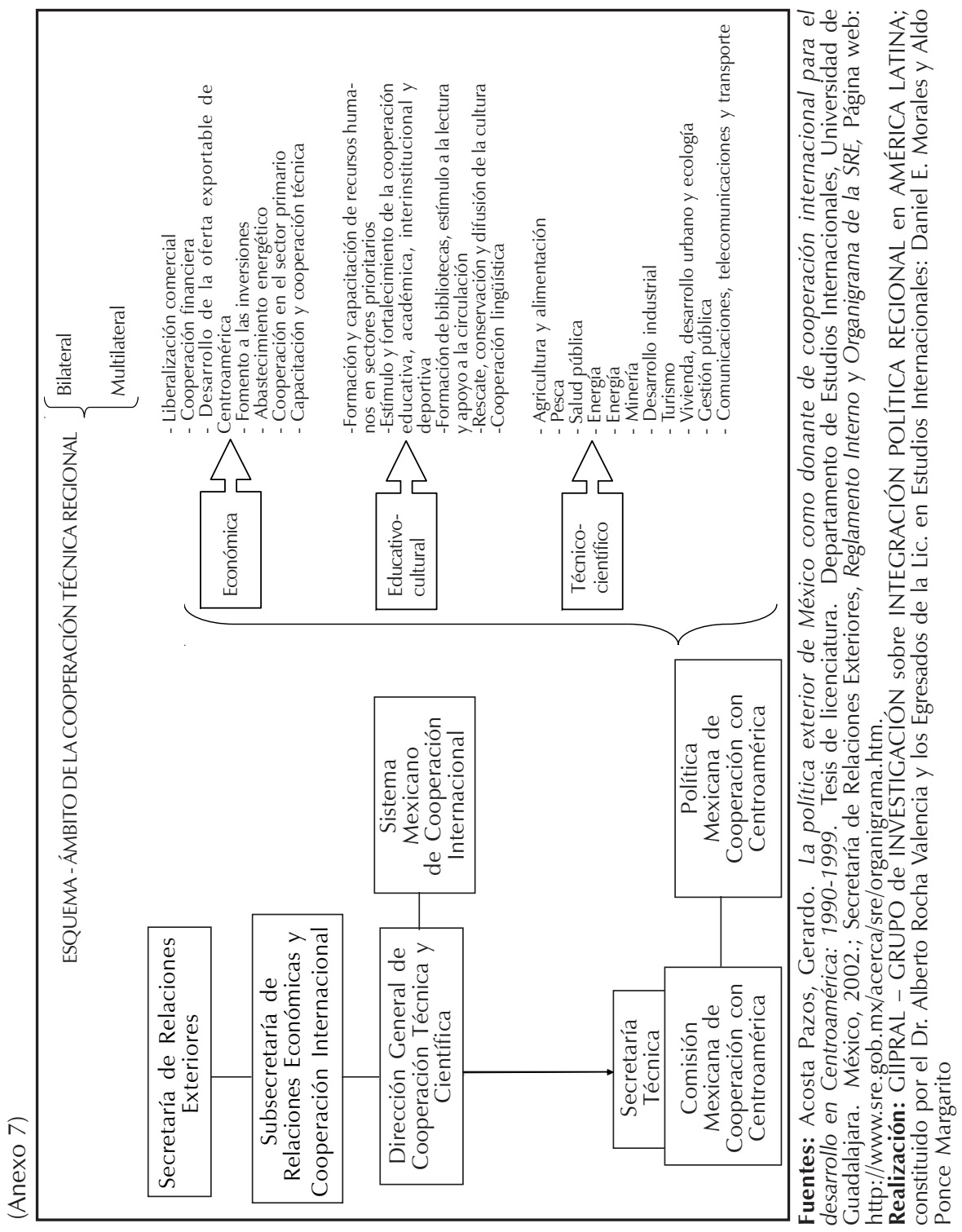


Anexo 8)

Cuadro - Cooperación económica y financiera de México con Centroamérica (1961-1996): proyectos realizados

\begin{tabular}{|c|c|c|c|}
\hline Período/países & 1991-1995 & Promedio 1991-1995 & 1996 \\
\hline Regionales & 34 & 6.8 & 2 \\
Belice & 35 & 7 & 0 \\
Costa Rica & 81 & 16.2 & 7 \\
El Salvador & 73 & 14.6 & 7 \\
Guatemala & 67 & 13.6 & 0 \\
Honduras & 54 & 10.8 & 1 \\
Nicaragua & 43 & 8.6 & 3 \\
Panamá & 0 & 0 & 3 \\
Total & 387 & 77.4 & 23 \\
\hline
\end{tabular}

Cuadro - Cooperación educativa y cultural de México con Centroamérica (1961-1996): proyectos realizados

\begin{tabular}{|c|c|c|c|}
\hline Período/países & 1991-1995 & Promedio 1991-1995 & 1996 \\
\hline Regionales & 162 & 32.4 & 5 \\
Belice & 287 & 57.4 & 16 \\
Costa Rica & 404 & 80.8 & 19 \\
El Salvador & 306 & 61.2 & 23 \\
Guatemala & 302 & 60.4 & 18 \\
Honduras & 244 & 48.8 & 16 \\
Nicaragua & 170 & 34 & 6 \\
Panamá & 0 & 6.6 & 17 \\
Total & 1,808 & 361.6 & 120 \\
\hline
\end{tabular}


Cuadro - Cooperación técnica y científica de México con Centroamérica (1961-1996): proyectos realizados

\begin{tabular}{|c|c|c|c|}
\hline Período/países & 1991-1995 & Promedio 1991-1995 & 1996 \\
\hline Regionales & 104 & 20.8 & 10 \\
Belice & 160 & 32 & 10 \\
Costa Rica & 355 & 71 & 59 \\
El Salvador & 363 & 72.6 & 26 \\
Guatemala & 611 & 122.2 & 31 \\
Honduras & 188 & 37 & 25 \\
Nicaragua & 481 & 96 & 51 \\
Panamá & 78 & 15.6 & 18 \\
Total & 2,340 & 468 & 230 \\
\hline
\end{tabular}

Fuentes: La Cooperación Mexicana con Centroamérica, 1991-1995, SRE, Comisión Mexicana para la Cooperación con Centroamérica, México, 1996; La Cooperación Mexicana con Centroamérica, 1996, SRE, Comisión Mexicana para la Cooperación con Centroamérica, México, 1997. Cuadros estadísticos obtenidos de: Acosta Pazos, Gerardo. La política exterior de México como donante de cooperación internacional para el desarrollo en Centroamérica: 1990-1999. Tesis de licenciatura. Departamento de Estudios Internacionales, Universidad de Guadalajara. México, 2002.

La característica central de esta cooperación multilateral y bilateral está marcada por el hecho de que México es un país donante de cooperación y Centroamérica es un conjunto de países receptores de cooperación internacional. Los cuadros que acabamos de presentar nos permiten sustentar estas ideas. Además, todavía se puede añadir que dicha cooperación es multidimensional y contribuye con el desarrollo general de la región centroamericana y con el desarrollo particular de cada uno de los países centroamericanos.

Ámbito económico, comercial y financiero

En el Cuadro "Tratados y Acuerdos Comerciales de México" aparecen aquellos firmados con los países de Centroamérica. El primer TLC fue el firmado con Costa Rica en 1994, y entró en vigencia en 1995. El segundo 
TLC fue firmado con Nicaragua en 1997, y entro en vigencia en 1998. El tercer TLC fue firmado con los países de Guatemala, Honduras y El Salvador o el Triángulo del Norte en 2002, y entró en vigencia en 2002. Finalmente existe un cuarto TLC que se está negociando con Panamá desde 1996. ¿Por qué cuatro TLC's con una región pequeña? Lo primero que salta a la vista es que en éste ámbito se han privilegiado negociaciones y relaciones de carácter bilateral, cuando una negociación multilateral habría sido suficiente. Y muy posiblemente la explicación se encuentre dentro de la región centroamericana misma: desacuerdos y rivalidades entre los gobiernos y las elites políticas centroamericanos.

En este apartado no nos abocaremos al análisis del comercio realizado en cada uno de esos cuatro TLC's. Solamente, en base al Cuadro: México, importaciones y exportaciones con cada una de las regiones del mundo (1993-2002), que se encuentra en el anexo, nos aproximaremos a la cifras generales del comercio entre México y Centroamérica. Ya hemos escrito que Centroamérica, en la jerarquía de su comercio con las diferentes regiones del mundo, ocupa el sexto lugar en las exportaciones y el quinto lugar (junto a Oceanía y las Antillas) en las importaciones. Las exportaciones de México hacia Centroamérica, en el periodo de 1993-2002, prácticamente se mantienen estables y representan un porcentaje promedio de $1.1 \%$ de las exportaciones totales de México. Las importaciones de México respecto de Centroamérica, en el mismo periodo, tienden a crecer un poquito en los últimos años y representan un porcentaje promedio de $0.2 \%$ de las importaciones totales de México. Como resultado de estos intercambios comerciales, la balanza comercial de México siempre fue positiva.

En cuanto a inversión de capitales y participación de empresas de México en Centroamérica, no contamos con los datos suficientes para hacer mayores desarrollos. Pero si sabemos que Costa Rica es el país privilegiado de la inversión de capitales y de la participación de las empresas de México; Guatemala sigue de muy lejos. 


\section{A modo de conclusiones: razones y sustentos de la hegemonía regional mexicana}

Antes de ensayar algunas conclusiones, consideramos relevante colocar frente a frente a México, la región Sur-Sureste de México, a Centroamérica y a los país centroamericanos. El Cuadro comparativo, México Centroamérica, 2002 (ver figura 9) servirá de base para nuestros desarrollos. Si colocamos a México frente a Centroamérica en función de seis variables, los resultados que encontramos son los siguientes: Centroamérica es respecto de México $26.57 \%$ de su territorio, $36.66 \%$ de su población, $16.39 \%$ de su PIB, $52.27 \%$ de su PIB Per Cápita, $13.55 \%$ de sus importaciones y $7.8 \%$ de sus exportaciones.

Estamos, entonces, ante la relación de un país grande con una región pequeña. Por ello, México ha comprometido solamente una de sus mesoregiones, el Sur Sur-Este, ${ }^{28}$ en el proceso de vinculación e integración con Centroamérica. El Sur Sur-Este de México sí es equiparable con Centroamérica y el conjunto de países que forman esta región. A la vez, este es el punto de partida de la hegemonía regional y de la geopolítica y de la geoeconomía de México con Centroamérica. En todo este entramado de relaciones, cuyo marco institucional es el Mecanismo de Diálogo y Concertación de Tuxtla (con sus cuatro ámbitos de acción), se apuesta por el desarrollo de la mesoregión Sur Sur-Este de México y por el desarrollo de la región de Centroamérica, y en esa apuesta se insertan las proyecciones geopolíticas y geoeconómicas de México.

Además, México cuenta con reales sustentos para sus proyecciones geopolíticas sobre la región Centroamericana: 1. Mesoamérica (Sur Sur-Este

28 Consultar Gobierno de los Estados Unidos Mexicanos: Plan Nacional de Desarrollo 2001-2006, Presidencia de la República, México, 2001. En este documento oficial se anota lo siguiente: “Las mesoregiones son las unidades base del sistema de planeación para el desarrollo regional; se componen de varias entidades federativas que en forma práctica se integran para coordinar proyectos de gran envergadura con efectos que trascienden los límites de dos o más entidades federativas" (p. 10). Y en seguida se mencionan cinco mesoregiones: Sur Sur-Este, Centro-Occidente, Centro, Noreste y Noroeste. 
Sociologias, Porto Alegre, ano 8, no 16, jul/dez 2006, p. 308-359

\begin{tabular}{|c|c|c|c|c|c|c|c|}
\hline 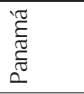 & $\begin{array}{l}8 \\
\infty \\
\wedge \\
\wedge\end{array}$ & 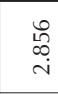 & $\begin{array}{l}0 \\
i n \\
0 \\
0\end{array}$ & 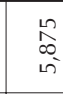 & $\begin{array}{l}\stackrel{\Omega}{m} \\
m^{2}\end{array}$ & 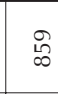 & \multirow{12}{*}{ 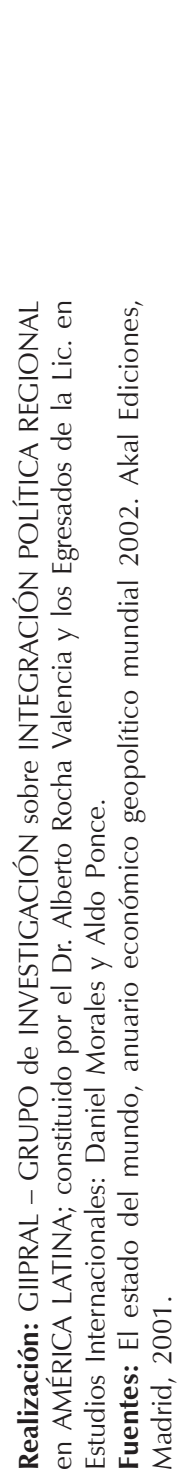 } \\
\hline 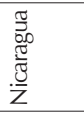 & $\begin{array}{l}8 \\
8 \\
- \\
-\end{array}$ & $\begin{array}{l}\bar{T} \\
\text { ô } \\
\text { Lे }\end{array}$ & $\underset{\check{\Sigma}}{\check{\Sigma}}$ & 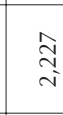 & 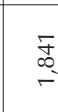 & $\tilde{\hat{~}}$ & \\
\hline 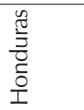 & 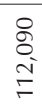 & $\frac{1}{\dot{f}}$ & $\begin{array}{l}8 \\
\stackrel{0}{1} \\
\text { J }\end{array}$ & 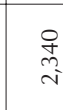 & 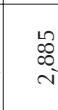 & $\underset{\sim}{\sim}$ & \\
\hline 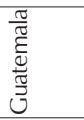 & $\begin{array}{l}8 \\
\circ \\
00^{\circ} \\
0 \\
0\end{array}$ & 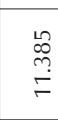 & $\begin{array}{l}\tilde{T} \\
\hat{N} \\
\text { ó } \\
+\end{array}$ & 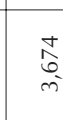 & 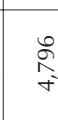 & $\begin{array}{l}\hat{6} \\
\stackrel{i}{i}\end{array}$ & \\
\hline 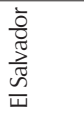 & $\begin{array}{l}\text { o } \\
\text { ¿ } \\
\text { i }\end{array}$ & 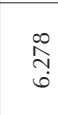 & $\begin{array}{l}\tilde{N} \\
\tilde{N} \\
\tilde{\sigma} \\
\tilde{N}\end{array}$ & 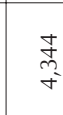 & 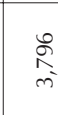 & $\stackrel{\stackrel{F}{m}}{\sim}$ & \\
\hline $\begin{array}{l}\frac{\pi}{2} \\
\frac{\pi}{0} \\
0 \\
0\end{array}$ & $\begin{array}{l}8 \\
£ \\
0 \\
0\end{array}$ & 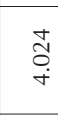 & $\begin{array}{l}\infty \\
\stackrel{\infty}{1} \\
\bar{m}\end{array}$ & $\begin{array}{l}\stackrel{8}{\circ} \\
\infty \\
\infty\end{array}$ & 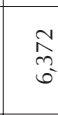 & 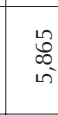 & \\
\hline$\frac{\mathscr{U}}{\mathscr{\Xi}}$ & 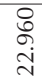 & $\begin{array}{l}\text { ָี } \\
\text { I }\end{array}$ & $\underset{\sim}{\stackrel{ \pm}{\sim}}$ & \begin{tabular}{l}
$\stackrel{\leftrightarrow}{\alpha}$ \\
\multirow{\sigma}{*}{}
\end{tabular} & ㅇํㅁ & $\stackrel{ \pm}{\sigma}$ & \\
\hline 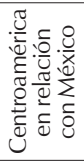 & 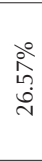 & 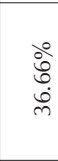 & $\begin{array}{l}\text { oे } \\
\text { ஸె } \\
\sigma\end{array}$ & 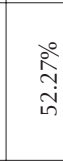 & 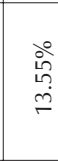 & $\frac{\stackrel{\circ}{\infty}}{\stackrel{\infty}{\Lambda}}$ & \\
\hline 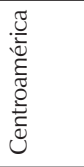 & 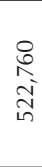 & 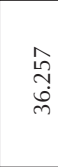 & \begin{tabular}{l}
$\stackrel{2}{\sigma}$ \\
N \\
\multirow{I}{\tau}{}
\end{tabular} & \begin{tabular}{l}
$\frac{5}{6}$ \\
\multirow{+}{*}{}
\end{tabular} & $\begin{array}{l}\frac{\sigma}{L} \\
\tilde{\nu}\end{array}$ & $\begin{array}{l}\text { Iै } \\
\text { I } \\
\text { İ }\end{array}$ & \\
\hline 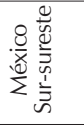 & 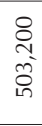 & $\stackrel{\sim}{\sim}$ & வேं & 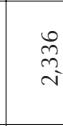 & & $\begin{array}{l}8 \\
\stackrel{8}{\circ} \\
m \\
\end{array}$ & \\
\hline $\begin{array}{l}\frac{8}{x} \\
\frac{0}{z}\end{array}$ & 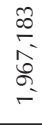 & $\begin{array}{l}\sigma \\
\infty \\
\infty\end{array}$ & $\begin{array}{c}8 \\
\substack{\alpha \\
N \\
\infty \\
\infty}\end{array}$ & $\begin{array}{l}\text { 尺) } \\
\text { o } \\
\infty^{\circ}\end{array}$ & 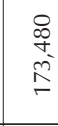 & 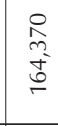 & \\
\hline & 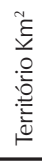 & 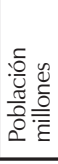 & $\begin{array}{l}\text { S } \\
\text { 产 } \\
\overline{\bar{\varepsilon}} \\
\stackrel{\emptyset}{\alpha}\end{array}$ & 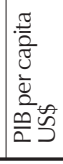 & 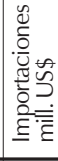 & 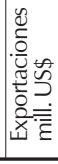 & \\
\hline
\end{tabular}


mexicano y Centroamérica) es un espacio étnico-cultural maya, cuanta con un pasado colonial común y es habita de pueblos indios emergentes. 2. El Estado de Chiapas (anteriormente parte de Centroamérica) es un "nexo" entre el Sur Sur-Este mexicano y Centroamérica y un "nexo" entre México y Centroamérica. 3. Mesoamérica es una región de pobreza y subdesarrollo y una en donde se originan flujos migratorios hacia Norteamérica. 4. Centroamérica no es un "patio trasero" para México, es un espacio regional que le permite continuidad y fluidez. 5. Centroamérica es un mercado vecino interesante para el comercio y las inversiones mexicanas. 6. Centroamérica es un conjunto de países con los que México podría contar en el momento de las negociaciones finales del ALCA.

\section{Referências}

BORGES, Alfredo Guerra. La integración centroamericana ante el reto de la globalización (antología). CRIES, Managua, p. 58. 1996.

CASTAÑEDA, Jorge G. Apuntes de política exterior para el gobierno de Vicente Fox: 2000-2006. In: ELIZONDO, Carlos y MAIRA, Luis (editores). Chile-México, dos transiciones frente a frente. CIDE, México D.F. 2000.

CASTAÑEDA, Jorge G. Los ejes de la política exterior de México. Revista Nexos, México D.F, diciembre. 2001.

CHABAT, Jorge. La integración de México al mundo de la posguerra fría: del nacionalismo a la interdependencia imperfecta. In: BORJA, A.; GONZÁLEZ, G. y B. STEVENSON, J. R. (Coordinadores). Regionalismo y poder en América: los límites del neorrealismo. CIDE/Miguel Ángel Porrua, México D.F. 1996

CUMBRE DE TUXTLA I: Declaración de Tuxtla Gutiérrez, Tuxtla GutiérrezChiapas, México, 10 y 11 de enero de 1991. <http://www.sgsica.org/ reuniondepresidentes/documentos/declara-tuxtla-I.html>.

CUMBRE DE TUXTLA II: Declaración Conjunta y Plan de Acción de la reunión de Jefes de Estado y de Gobierno de Centroamérica y de México, San José, Costa Rica, 15 y 16 de febrero de 1996. <http://www.sgsica.org/ reuniondepresidentes/documentos/declara-tuxtla-II.html> 
CUMBRE DE TUXTLA III. Declaración Conjunta de los Jefes de Estado y de Gobierno de los Países integrantes del Mecanismo de Diálogo y Concertación de Tuxtla. San Salvador, El Salvador, 17 de junio de 1998. <http://www.sgsica.org/ reuniondepresidentes/documentos/declara-tuxtla-III.html $>$

CUMBRE DE TUXTLA IV. Declaración Conjunta de los Jefes de Estado y de Gobierno de los Países integrantes del Mecanismo de Diálogo y de Concertación de Tuxtla. Ciudad de Guatemala, Guatemala, 25 de agosto de 2000. < http:// www.sgsica.org/reuniondepresidentes/documentos/declara-tuxtla-IV.html>

CUMBRE DE TUXTLA V. Declaración Conjunta de los Jefes de Estado y de Gobierno de los Países integrantes del Mecanismo de Diálogo y Concertación de Tuxtla. Mérida, México, 27 y 28 de junio de 2002. < http://www.seg.gob.mx >

CUMBRE EXTRAORDINARIA DE TUXTLA. Declaración conjunta de los Jefes de Estado y de Gobierno de los Países integrantes del Mecanismo de Diálogo y Concertación de Tuxtla. San Salvador, El Salvador, 15 de mayo de 2001. < http:/ /www.sgsica.org/reuniondepresidentes/documentos/declara-ca-tuxtla.html>

FLORES, Rafael Velásquez (coordinador). El proyecto de política exterior de Vicente Fox: ¿Continuidad o Cambio? In: La política exterior de México bajo un régimen democrático. ¿Cambio o continuidad? México: Plaza y Valdés. 2002.

KEOHANE, Robert O. Instituciones internacionales y poder estatal. Ensayos sobre teoría de las relaciones internacionales. GEL, Argentina. 1993.

KEOHANE, Robert O. y NYE, Joseph S. Poder e interdependencia. La política mundial en transición, GEL, Argentina .1988.

NYE, Joseph S. Poder y estrategia de Estados Unidos después de Irak. In: Revista Foreign Affairs en Español, Itam,v.3, n. 3, México D.F., julio-septiembre. 2003.

OJEDA, Mario. Alcances y Límites de la Política Exterior de México (El Colegio de México, México D.F. 2001.

ROCHA,Alberto. Configuración política de un mundo nuevo. Dimensiones políticas de lo global, lo suprarregional, lo posnacional y lo local, Universidad de Guadalajara, Jalisco-México. 2003.

ROCHA, Alberto. El posicionamiento débil y disperso de América Latina y el Caribe ante el Área de Libre Comercio de las Américas. Revista Cenarios, São Paulo. n. 3, Grupo de Estudos Interdisciplinares sobre Cultura e Desenvolvimento, Universidade Estadual Paulista, Brasil, 2001-2002. 
ROCHA, Alberto. México y Brasil en el proceso de integración regional de América Latina y el Caribe: ¿Rol de dos subhegemones? Revista Liminar, Chiapas, n. 1, Centro de Estudios Superiores de México y Centroamérica, Universidad de Ciencias y Artes de Chiapas, México, junio. 2003.

ROJAS, Asmara González. Análisis comparativo de los fundamentos de la Política Exterior Estadounidense y Mexicana. Tesis de Licenciatura en Relaciones Internacionales, Departamento de Estudios Sociopolíticos y Jurídicos, Instituto Tecnológico y de Estudios Superiores de Occidente-ITESO, abril. 2003.

SANDOVAL, Érika Ruiz. La política exterior de México con Vicente Fox. Revista Este País, México, n. 145, abril. 2003.

SOLÍS, Daniel Villafuerte. Integraciones comerciales en la frontera sur. Chiapas frente al Tratado de Libre Comercio México-Centroamérica. UNAM/PRIMMSE, México, p. 305. 2001.

MERLOS, Carlos Orellan. Plan Puebla-Panamá, Boletín n. 193. < http:// www.fusades.com.sv/investigacion_economica/decs/documentos/bol193.pdf >

\section{Resumen}

México como Brasil (primera década del 2000) comenzaron a desplegar proyecciones geoeconómicas y geopolíticas sobre su entorno inmediato (la subregión de pertenencia) y su entorno mediato (la subregión vecina), además de jugar roles políticos destacados en su entorno lejano (la región latinoamericana y caribeña) y en su entorno remoto (el continente americano). En consecuencia, hemos propuesto y desarrollado las ideas de que estas situaciones y realidades son las de procesos de constitución de dos Estados con roles de "subhegemones", con sus respectivas funciones de "subhegemonía". Preguntamos: ¿Cómo y por qué México y Brasil se encuentran definiendo roles de "subhegemones"? ¿Son posibles tales roles y funciones en un espacio continental donde un Estado "superpotencia" ejerce una "supremacía" indiscutible, además de buscar redefinir su "hegemonía" (la que está en crisis)? 
Para trabajar el tema de las relaciones geopolíticas de México con Centroamérica realizamos cuatro aproximaciones: posicionamiento actual de México, antecedentes históricos de las relaciones, proceso de institucionalización de la cooperación y campo de acción de la relaciones. Además, se concluye el trabajo con algunas ideas sobre la visión geopolítica de México. La aproximación al posicionamiento estructural de México en el mundo y el continente americano, busca poner en evidencia las realidades de su condición de país semiperiférico y "subhegemón". La aproximación histórica conduce a la década de los años ochenta y a la década de los años noventa, donde se sientan los antecedentes y se inicia y profundiza la cooperación de México con Centroamérica. La aproximación institucional, centrada en la década de los años noventa e inicios de la primera década del año 2000, aborda el campo de acción de las relaciones geopolíticas y geoeconómicas de México con Centroamérica. Esta parte es central en el trabajo, pues se trata de analizar el Mecanismo de Diálogo y Concertación de TuxtlaGutiérrez y sus tres ámbitos de operación: 1. El ámbito político. 2. El ámbito del desarrollo. 3. El ámbito de la cooperación técnica regional. 4. El ámbito económico, comercial y financiero.

Palabras-clave: integración regional, hegemón, sub-hegemón, hegemonía, subhegemonía, política exterior, geoeconomía, geopolítica, cooperación, México, Centroamérica, Mesoamérica, sistema de integración de Centro América, Brasil, Estados Unidos.

Recebido: 01/06/05

Aceite final: 06/09/05 
INTERFACE INTERFACE

\section{Mexico's Geopolitics in Central America: Regional Hegemony?}

\section{Alberto Rocha}

M exico as well as Brazil (first decade of 2000) started to release geo-economic and geo-political projections about their unmediated surroundings (their region of belonging) and their mediated surroundings (their neighboring region), besides playing major political roles in their far surroundings (the Latin American and Caribbean region) and their remote surroundings (the American continent). As a result, we have proposed and developed the idea that such situations and realities are those of processes of constitution of States with "sub-hegemonic" roles, with their respective functions of "sub-hegemony". We therefore ask the following question: Why are both M exico and Brazil defining "sub-hegemonic" roles? Are such roles and functions possible within a continental space where a "superpower" exerts unquestionable "supremacy" besides seeking to redefine its "hegemony" (the one now undergoing a crisis)?

In order to work on the theme of Mexico's geopolitical relations with Central America, we have carried out four approximations: Mexico's current stance; historical background of the relations; process of institutionalization of cooperation; and field of action of the relations. Besides, the work is concluded with some ideas about M exico's geopolitical view. The approximation to M exico's structural stance in the world and in the American Continent seeks to highlight realities in its condition of semiperipheral and "sub-hegemonic" country. The historical approximation leads to the 1980s and the 1990s, when the background for M exico's cooperation with Central America is established and that cooperation is started and strengthened. The institutional approximation, focused on the 1990s and the early 2000s, approaches the field of action of M exico's geopolitical and geo-economic relations with Central America. This is the core part of the work, since it is the Mechanism for Dialog and Concertation of Tuxtla-Gutiérrez and its four levels of operation: 1. The political level; 2 . The development level; 3 . The level of regional technical cooperation; and 4 . The economical, comercial, and financial level.

Key words: Regional Integration, Hegemonic Countries, Sub-H egemonic Countries, Hegemony, Sub-Hegemony, Foreign Policy, Geo-Economy, Geopolitics, Cooperation, Mexico, Central America, Mesoamerica, System of Integration of Central America, Brazil, U nited States. 